\title{
The impact of e-learning, gender-groupings and learning pedagogies in biology undergraduate female and male students' attitudes and achievement
}

\author{
Firas Almasri ${ }^{1,2}$ \\ Received: 13 January 2022 / Accepted: 14 February 2022 / Published online: 4 March 2022 \\ (c) The Author(s) 2022
}

\begin{abstract}
This study aimed to compare female and male students' attitudes and achievements within different learning settings determined by e-learning and in-classroom learning modalities, collaborative (CL), and traditional (TL) learning pedagogies and investigated the effect of single-gender (SG) and mixed-gender (MG) grouping in an undergraduate biology course. 1375 biology students enrolled in a public university were randomly divided into 12 learning settings. Keller's ARCS model and Vygotsky's Socio-cultural Theory were the theoretical frameworks that guided this study. Results indicated that females attained higher achievement and more positive attitude towards biology in TL and CL sections in single-gender compared to mixgender classes; overall, academic achievements between females and males demonstrated a significant difference at $\mathrm{P}<.05$. Females students performed relatively low achievement and had a negative attitude toward biology in mix-gender CL groups (2 Females + 2 Males) compared to single-gender CL groups (4 Females) in in-classroom modality. E-learning attenuated the negative impact of mixed-gender grouping on female students within e-learning CL settings. The effect size value indicated that males benefited more than females from mixed-gender CL $(2 \mathrm{~F}+2 \mathrm{M})$ pedagogy in e-learning and in-classroom modalities. Thus, e-learning may encourage female students to overcome the socio-cultural barrier that leads them to feel reticence in mixed-gender groups. The study helps to understand the most suitable learning settings for female and male students to decrease gender disparities, reduce the negative influences of stereotypical threats in different socio-cultural environments, and develop learning strategies to further equalize opportunities for females and male students, promoting students' attitudes and achievement in undergraduate biology education.
\end{abstract}

Keywords E-learning · Collaborative learning · Traditional learning · Gender grouping $\cdot$ Attitudes $\cdot$ Achievement

Firas Almasri

f.almasri@warwick.ac.uk

Extended author information available on the last page of the article 

Abbreviations
EL E-learning
IC In-classroom
SG Single-gender
MG Mix-gender
CL Collaborative learning
TL Traditional learning

\section{Introduction}

Internet and the rapid improvements in communication technology have influenced a revolution in education in the past two decades (Almasri, 2022; Adams \& Morgan, 2007; Alonso et al., 2005; Austin, 2017; Kim \& Park, 2020; Rudestam \& SchoenholtzRead, 2010; Szymkowiak et al., 2021; Vision and Change in Undergraduate Biology Education 2010; Wang \& Chen, 2007; World Economic Forum, 2020). As a consequence, the e-learning modality has emerged (Clark-Ibáñez \& Scott, 2008; Li, 2020; Rudestam, 2004; Saba, 2005) and has greatly influenced the Science, Technology, Engineer, and Mathematics (STEM) disciplines in general and biology education in particular (Austin, 2017; Goldenfeld \& Woese, 2007; Vision and Change in Undergraduate Biology Education 2010; Woese, 2004). Many studies brought insights that well-designed e-learning biology courses can be as effective as their faceto-face counterparts (Biel \& Brame, 2016; Siemens et al., 2015). E-learning allows for greater flexibility, convenience in timing, and location for the benefit of both the instructor and students who cannot be physically present on campuses (Cavinato et al., 2021; Kim \& Park, 2020; Kim et al., 2012; Lipsey et al., 2012). A growing number of students are now opting for e-learning classes to traditional in-classroom (Paul \& Jefferson, 2019; Sun \& Chen, 2016). However, the gender gaps are becoming increasingly pronounced in biology courses, especially in dominant male cultures, requiring compelling studies to establish more suitable learning environments (Hewapathirana \& Almasri 2022; Paul \& Jefferson, 2019; Struyf et al., 2019) and pedagogies that would equalize chances for all students (Eddy \& Brownell, 2016; Eddy et al., 2014; Freeman et al., 2014b). In addition, the new difficulties in scientific education connected to gender inequality in many socio-cultural situations necessitate more in-depth study to uncover underlying core causes, contradictory gender identities, and socio-cultural influences (Beasley \& Fischer, 2012; Eddy \& Brownell, 2016). Moreover, each culture has its collection of beliefs and norms that follow, requirements, obstacles, and socio-cultural components that create its identity. What works in one nation may not work in another (Auerbach \& Andrews 2018; Mansour \& Al-Shamrani, 2015b). Students' learning attitudes and achievement in STEM disciplines in general, and biology in particular, are also influenced by their socio-cultural context (Brownell et al., 2013; Hagay et al., 2013; Mansour \& Al-Shamrani, 2015b) and social identities such as gender (Adams et al., 2018; Barone, 2011; Eddy et al., 2014, 2015; Harskamp et al., 2008; Takeda \& Homberg, 2014; Wehrwein et al., 2007).

Traditional learning pedagogy is one of the main reasons causing the loss of students from biology (Hansen, 1994; Tanner \& Allen, 2004), and in one study, it 
was shown it increased students' failure rates by 55\% (Biel \& Brame, 2016; Freeman et al., 2014a). Moreover, collaborative learning (CL) pedagogy engaged students in learning STEM (Freeman et al., 2014a; Petrescu et al., 2018; Sunitha.G and.H.M 2018) and brought higher learning achievements and more positive attitudes across all STEM disciplines (Biel \& Brame, 2016; Celik \& Bayrakceken, 2012; Crowe et al., 2008; Eddy et al., 2013, 2014; Freeman et al., 2014a; Tanner, 2013; Zhan et al., 2011). Although CL has been praised for boosting student learning, retaining STEM students, and satisfying several National Science Education Standards, it presents some shortcomings (Slavin, 1996a, 2010; van der Linden et al., 2000). Previous research has demonstrated that students may not always collaborate to facilitate learning (Rummel and Spada 2005; Wang et al., 2010) and that CL may not always result in equal learning gains or improved class performance for all students (Gnesdilow et al., 2013a) because a variety of characteristics can impact, such as gender (Almasri et al., 2021; Eddy \& Brownell, 2016), gender grouping (Gelbgiser \& Albert, 2018) and the learning environment (Al-Samarraie et al. 2018; Gogoulou et al. 2007; WAnG and Education 2009). Most of the studies performed considering a particular socio-cultural context and social identities showed a genderbased pattern within collaborative and traditional face-to-face learning settings in the United States (Gnesdilow et al., 2013b; Guo et al., 2018; Myaskovsky et al., 2005; Sormunen-Jones et al., 2000), the United Kingdom (Carli, 2001; Milliken and Martins 1996; Takeda \& Homberg, 2014), Netherlands (Harskamp et al., 2008) and China (Zhan et al., 2015b). In addition, the implementation of collaborative e-learning settings was similarly affected by gender-dependent patterns (Cen et al., 2016b) and the socio-cultural context (Al-Sharhan, 2018; Karafyllis, 2015b). However, little has been researched to gain insights into how such variables might affect students' attitudes and achievement within e-learning and in-classroom learning modalities outside western countries or China, like in conservative societies such as Gulf countries in the Middle East.

Gulf Cooperation Council member nations (GCC) region includes Saudi Arabia, Kuwait, Qatar, Bahrain, United Arab Emirates, and Oman, which share similar socio-cultural contexts with traditional and conservative societies characterized by gender segregation within schools and universities educational systems (Alsuwailan, 2006; Dakhli \& El-Zohairy, 2013; Dakhli et al., 2010; Lightfoot, 2014; Mansour \& Al-Shamrani, 2015b). Among the studies that tackled socio-cultural and gender issues within the educational field in the GCC countries, only our previous research brought quantitative insights about how gender-grouping affected female and male students' attitudes within in-classroom biology courses delivered under a collaborative and traditional pedagogy (Almasri et al., 2021). However, Almasri's (2021) study considered major and non-major biology students toward face-to-face learning modality and did not shed light on the e-learning modality. Al-Kaabi (2016) performed a comprehensive study at Qatar University (QU) and showed a significant difference in implementing collaborative versus traditional learning in e-learning and in-classroom modalities. Nevertheless, this study did not distinguish between students' gender nor addressed gender-grouping (Al-kaabi 2016b). Nicole (2015) argued how tertiary education in the Middle East is widely delivered through the traditional pedagogy and brought some insights about the effects of gender and culture in STEM (Karafyllis, 2015a). Mansour 
(2015) established the effect of socio-cultural factors that influence engagement and non-engagement on science education and gave examples based on current policies, educational reforms, innovative practices, and challenges in science education in some GCC countries (Mansour \& Al-Shamrani, 2015b). However, non-comprehensive research that could bring quantitative data about the effect of such factors on undergraduate students was carried out, and instead, it mainly tackled the issues from a theoretical point of view.

Thus, it is critical to fill in this literature gap since context-based knowledge is crucial to formulate the best evaluation of the quality and effectiveness of learning pedagogies and the learning environment considering gender and gender grouping variables to design and conduct biology courses for each learner. GCC countries are faced with the unique opportunity to incorporate e-learning to help attenuate the impact of social identities and social-culture differences between female and male students in such conservative and gender-segregated cultures. This paper responded to the need to address these issues and was designed to compare female and male students' attitudes and achievements within different learning settings determined by e-learning and in-classroom instructional modalities, collaborative and traditional learning pedagogies, single-gender and mix-gender groupings in a gender-segregated educational system.

\section{Literature review}

\subsection{Attitude towards learning: Motivational theory, the ARCS model}

Students who are motivated to study will achieve better success than those who are not in every learning environment (Indriwati et al., 2019; Owens et al., 2020). Keller (2010) defined motivation as "that which explains the direction and magnitude of behavior, or in other words, it explains what goals people choose to pursue and how actively or intensely they pursue them" (Keller, 2010). It is well evidenced that pedagogical practices in science are heavily rooted in the traditional pedagogy (Tanner, 2013; Tanner \& Allen, 2004, 2006), and many institutions still teach biology through lectures and practices, which makes it difficult for instructors to engage and motivate students (Kuit \& Fildes, 2014). As a result, students have less or no motivation to apply the learned experience in real-life settings (Adom et al., 2017; Thirteen Edition Online 2004). Therefore, motivation is an essential element, especially for students within collaborative settings where they have to know why they need to learn the content and the benefits they will achieve by doing so (Adom et al., 2017; Indriwati et al., 2019; Kim, 2005; Owens et al., 2020; Ramirez, 2018).

According to Keller's Motivational Theory or "ARCS" Model (Keller, 1984), the four components or categories, namely Attention, Relevance, Confidence, and Satisfaction, encompass the major factors that influence the motivation to learn (Keller, 1984, 2010). Attention is related to capturing students' interests on the learning topic and then stimulating their curiosity to learn to sustain their attention (Keller et al., 2017; Means et al., 1997). Relevance is related to students' beliefs that the instruction will help them meet personal goals, needs, or motives (Chang 
and Lehman, 2002; Keller, 2010). Confidence also plays a vital role in ensuring students' motivation because if they are not appropriately motivated due to too little or too much confidence, they will not learn effectively (Keller, 2010; NaimeDiefenbach, 1991). If the first three motivational goals are achieved, students will be motivated to learn; however, to ensure students' continuous desire to learn, it is necessary to acquire the fourth category of the ARCS model, satisfaction (Gormley et al., 2012; Keller, 2010). As Keller (2010) suggested, students' satisfaction can result from extrinsic and intrinsic factors. Extrinsic factors include grades, opportunities for advancement, certificates, and other material rewards. In contrast, intrinsic factors include positive interactions with other people, having their views heard and respected, and accomplishments that people may receive and make enhance their feelings of self-esteem (Gormley et al., 2012; Keller, 2010). This theory allowed us to analyze how students' attention, relevance, confidence, and satisfaction towards the course, and thus, their overall attitudes, were affected by the learning modalities, learning pedagogies, and gender-grouping within the Gulf region society.

\subsection{Socio-cultural context of the study}

When evaluating the best quality and effectiveness of pedagogies to design biology courses for each learner, it is indispensable to consider each particular socio-cultural context and adopt a pedagogical approach from another culture (Carter, 2008; Lantolf \& Thorne, 2006; Mansour \& Al-Shamrani, 2015a; Wang \& Degol, 2017). Despite schools applying the same curriculum, socio-cultural variances must be taken into account to guarantee that it is relevant and fits into students' and instructors' socio-cultural and religious backgrounds (Almasri et al., 2021; Brownell et al., 2013; Hagay et al., 2013; Mansour \& Al-Shamrani, 2015b; Pham Thi Hong, 2011) because it leads to rooted differences in students' social identities between females and males (Alsuwailan, 2006; Baram-Tsabari \& Kaadni, 2009; McClusky, 2017). Social identity refers to a person's awareness of belonging to a social category or group (Hogg \& Abrams, 1988). In this study, gender is the social identity that shapes females' and males' norms, attitudes, and behaviours. Thus, it is likely that in a conservative society such as in GCC countries, the rooted differences between female and male students could affect their attitudes in terms of attention, relevance, confidence, and satisfaction and behaviours, which would consequently affect their achievement in biology.

Vygotsky's Socio-cultural Theory provides the epistemological frame to consider the particular socio-cultural context in which the study took part (Vygotsky, 1978, 1997). We selected Kuwait as a case of study to represent the society in the GCC region. These countries share a similar socio-cultural context characterized by differences between females and males that are deeply rooted in people's idiosyncrasy, the country's daily life, and even within the governmental and educational systems (Ahmed, 2020; Alsuwailan, 2006; Bystrov et al. 2021; Dakhli et al., 2010; Dakhli \& El-Zohairy, 2013; Lightfoot, 2014). Single-gender classrooms are the norm at all stages of education in such institutions, from kindergarten through graduate school, and mixed-gender classes are rarely employed at the college level (Abdeldayem 
\& Al Dulaimi, 2020; Ahmed, 2020; Al-Khaldi 2007b; Dakhli et al., 2010). The gender segregation factor results in a lack of interaction, a lack of confidence in communication, and a lack of opportunity to meet and exchange ideas with peers of the opposite gender, especially for female students who are most affected by stricter rules of interaction and communication (Al-Fadhli, 2008; Khan et al., 2017). As a consequence of the deeply rooted differences between female and male students, the balance between the categories of the ARCS model that determine overall attitudes towards learning might be affected, which would lead students not to be correctly motivated and to arise negative attitudes (Keller, 1984, 2010). Ultimately, students' achievement could be negatively affected since there is a widely reported positive correlation between attitudes and achievement. Vygotsky also outlined the value of meaningful relationships within participants during the active process of learning (Vygotsky, 1978). Moreover, evidence supports this statement because it was shown that interpersonal relationships play a substantial role in students' capacity to perform effectively and succeed in their academic lives (Creasey et al., 1997; Field et al., 2002; Marjoribanks, 1996; Martin et al., 2007; Robinson, 1995). Nevertheless, this assumption needs to be carefully considered within the conservative socio-cultural context of the study, where interpersonal relationships between female and male students are not usual (Alsuwailan, 2006; Dakhli et al., 2010).

Despite the unique socio-cultural context and the rooted social identities between females and males in GCC countries, the university's educational structure, curricula, methods, and standards are based on the American model of higher education(Al-Khaldi 2007b; Singera et al., 2014). Therefore, this study aimed to implement CL and TL pedagogies on e-learning and in-classroom learning environments and investigate the effect of single-gender (female and male students were separated) and mixed-gender groups (female and male students interacted with each other) towards students attitudes and achievement in biology undergraduate classes.

\subsection{Impact of gender and gender-grouping on students' attitudes and achievement in biology.}

The GCC countries face the great opportunity to take advantage of the educational revolution STEM disciplines have undergone in the past two decades, greatly influenced by the internet, new technologies, and the collaborative pedagogical approach (Austin, 2017; Bensaid \& Brahimi, 2020; Vision and Change in Undergraduate Biology Education 2010), to ensure more students have access to education, maintain high educational standards leading to enhanced learning, support new pedagogical practices, and adapt them to their particular cultures (Al-Fadhel et al., 2020; Omari, 2017). Therefore, context-based studies are needed to gain solid insights into how students' attitudes and achievements would be affected in different learning settings within gender-segregated educational systems. This is a critical topic to handle since, among other things, in many GCC countries students often lack opportunities to meet freely, to communicate and to collaborate with their peers, especially female students who are subjected to stricter rules of interaction and communication (Al-Fadhli, 2008; Al-kaabi, 
2016; Mansour \& Al-Shamrani, 2015b). Consequently, students may develop shyness and lack of confidence to express an opinion in front of members of the opposite sex, which might affect their attitudes towards the course and, ultimately, their achievement in the subject (Al-kaabi, 2016; Al-Sharhan, 2018). Therefore, GCC students' attitudes and achievement would likely be differentially affected in those learning settings where female and male students should interact collaboratively in face-to-face single-gender or mix-gender groups. At this point arises the issue of whether e-learning would help overcome the socio-cultural limitation by providing alternate means of interaction in which students do not need to interact face-to-face. The literature below is organized into two main sections, in-classroom and e-learning instructional modalities, addressing how socio-cultural, gender, and gender grouping factors affected students' attitudes and achievement in traditional and collaborative biology learning settings. We also tackled the differences observed between western countries versus GCC countries.

\subsubsection{In-classroom learning modality}

Traditional learning and collaborative learning in a classroom Traditional learning (TL) is an activity-based strategy in which teachers plan and manage the whole class, lead every stage of the learning process, define the investigation questions and processes, and seek to direct students, develop thinking, and provoke curiosity (Dawkins et al., 2017; Ruegg, 1992). The TL environments are based on exposition-centered methods (Thirteen Edition Online 2004), where students have a passive role because they receive knowledge as empty vessels to be filled with learning (Reeves \& Reeves, 1997). Dialogue within participants is scarce because students are isolated from all social interactions (Adom et al., 2017; Thirteen Edition Online 2004). In general, undergraduate biology courses are based on this pedagogy and thus, are fact-oriented, instructor-centered, and lecture-based (Wood, 2009), which difficulties helping students develop higher-level cognitive skills (Momsen et al., 2010). Science instructors feel identified with the TL pedagogy (Alam \& Jackson, 2013; Biel \& Brame, 2016) because they can transmit the large body of accrued scientific knowledge with lectures, and the problem is not the lectures but that instructors overuse them (Powell, 2003; Tanner \& Allen, 2004, 2006). However, evidence indicates that U.S. students gained superficial knowledge from traditional methods of instruction and that this pedagogy could be one reason for the high attrition rates among introductory students in STEM disciplines (Halloun \& Hestenes, 1985; Hestenes et al., 1992; Wood, 2009). A similar situation is observed in the GCC countries, where the educational systems are based primarily, if not exclusively, on the traditional pedagogy (Al-kaabi 2016a; Mansour \& Al-Shamrani, 2015b). As a result, GCC students have faced low mean performance on internationally comparative assessments of mathematics and science (Barber et al., 2007; Dakhli \& ElZohairy, 2013). In particular, in Kuwait, 93\% of the science classes are taught using the traditional pedagogy (Al-Kandari, 2006), which has been linked to students' relatively low achievements and attitudes in biology (Ahmad \& Greenhalgh-Spencer, 2017b; Al-kaabi, 2016; Al-Khaldi 2007b; Almasri et al., 2021).

Collaborative pedagogy (CL) represents a significant shift away from the traditional "teaching by telling" approach (Indriwati et al., 2019; Mohamad Said et al., 
2014; Ruegg, 1992; Swanson et al., 2021; Thirteen Edition Online 2004) because it teaches students how to think and understand (Petrescu et al., 2018; Thirteen Edition Online 2004) through activities within an authentic, real-world context (Dogru \& Kalender, 2007). In addition, the CL is student-based since students play an active role in the learning process (Gamoran et al., 2000); communication and the sharing of ideas in group projects are crucial elements of collaborative classrooms, which develop interpersonal relationships and communication skills by establishing an atmosphere that promotes collaboration and the interchange of ideas (Petrescu et al., 2018; Swanson et al., 2021; Thirteen Edition Online 2004). Collaborative pedagogy has been recognized as one of the most effective pedagogical techniques for teaching science because it promotes students' positive attitudes and higher achievements across all of the STEM disciplines (Ajaja, 2013; Ajaja \& Eravwoke, 2010; Biel \& Brame, 2016; Celik \& Bayrakceken, 2012; Crowe et al., 2008; Eddy et al., 2013, 2015; Freeman et al., 2014a; Johnson et al., 2000; Lord, 1997; Ruta, 2014; Springer et al., 1998; Tanner, 2013; Zhan et al., 2011), and it benefits STEM undergraduates by enhancing their conceptual understandings, their critical thinking skills, and their persistence in STEM fields (Kuit \& Fildes, 2014).

It is necessary to gain knowledge on how the interactions through collaboration among students could affect their attitudes and their achievement when learning within single-gender and mix-gender groups. Moreover, an especial look needs to be taken to analyze the effect of CL on female students since in the GCC countries, they are subjected to stricter rules of interaction and communication what might affect their confidence and satisfaction towards the course, ultimately interfering in their attitudes and achievement (Al-Fadhli, 2008). In addition, Kuwait is experiencing a growing number of students, especially females, who look to pursue biology education (Ahmad \& Greenhalgh-Spencer, 2017a; Al-Khaldi, 2007). Therefore, it is necessary to accompany female students through the most conducive pedagogies.

Impact of gender and gender-grouping in-classroom Students' learning attitudes and achievement in biology are also influenced by other factors rather than learning pedagogies and instructional modalities, including socio-cultural context (Brownell et al., 2013; Hagay et al., 2013; Mansour \& Al-Shamrani, 2015b) and social identities such as gender (Adams et al., 2018; Barone, 2011; Eddy et al., 2014, 2015; Harskamp et al., 2008; Takeda \& Homberg, 2014; Wehrwein et al., 2007). Ample evidence demonstrates how gender plays a role in the learning process, engagement, and motivation for higher education (Barone, 2011; Conger \& Long, 2010; Grebennikov \& Skaines, 2009; Pirmohamed et al., 2017). Female students are more committed to university life; they spend more time preparing for classes, studying, and reading (Grebennikov \& Skaines, 2009) and prefer collaborative learning more than male students (Lundeberg \& Moch, 1995; Opdecam et al., 2014; Stump, Hilpert, et al., 2011). Gender plays a role in collaborative classroom learning settings because students need to interact face-to-face, affecting their attitudes and achievements in science courses (Cen et al., 2014; Chennabathni \& Rejskind, 1998; Colbeck et al., 2001; Opdecam et al., 2014; Stump, Hilpert, et al., 2011). The effect of gender-grouping was observed in many western countries, including the U.S. (Gnesdilow et al., 2013b; Guo et al., 2018; Myaskovsky et al., 2005; 
Sormunen-Jones et al., 2000; Xie et al., 2015b), the U.K. (Carli, 2001; Milliken \& Martins, 1996; Takeda \& Homberg, 2014), and the Netherlands (Harskamp et al., 2008). For instance, Gnesdilow et al., (2013a, 2013b) found that students in mixed-gender groups performed significantly higher than students in same-gender groups within in-classroom physics classes (Gnesdilow et al., 2013b). Takeda and Homberg (2014) observed that female and male students in mixed-gender balanced groups (two female and two male students) displayed enhanced collaboration. However, male students within single-gender groups and mix-gender groups with one male student underperformed and showed reduced collaborative behaviors (Takeda \& Homberg, 2014). For their part, Harskamp et al. (2008) studied the effect of gender-grouping on female and male performance in problem-solving in science within learning pairs and found that female students in the all-female pairs did not differ in performance from males; they underperformed in the mixedgender pairs (Harskamp et al., 2008). In contraposition, Xie et al. (2011; Xie et al., $2015 \mathrm{a}, \mathrm{b})$ did not find significant differences in students' achievement in science according to different gender grouping arrangements (Xie and Technology 2011; Xie et al., 2015a). However, few studies have been performed in conservative Gulf Cooperation Council (GCC) countries, which are characterized by a distinct social setting than western countries. For instance, in a previous study, we found that the collaborative teaching pedagogy, gender, and gender-grouping variables impacted major and non-major students' attitudes in a face-to-face biology course (Almasri et al., 2021). Male students demonstrated more positive attitudes towards biology within mixed-gender groups, while female students preferred single-gender groups (Almasri et al., 2021). Nevertheless, more studies need to be performed to gain context-based knowledge on how gender and gender-grouping might affect female and male students' attitudes and achievement within different learning settings, e-learning versus in-classroom learning in the GCC conservative countries.

\subsubsection{E-learning modality}

Traditional and collaborative learning within an e-learning environment If instructors in the traditional e-learning modality replicate traditional practices, they will facilitate a lecture-based, instructor-centered virtual environment with scarce dialogue among participants, and instead, students will be learning individually (Andrews-Graham, 2018; Duffy \& Kirkley, 2003). However, different styles of virtual classrooms that favor collaborative environments are evolving (Scharf, 2015) and can be either asynchronous or synchronous in the delivery (Huffman et al., 2005; Keengwe \& Kidd, 2010; Kelly, 2012; Martin et al., 2012; Parrish et al., 2021; Roberts, 2003). In asynchronous learning, students access course materials on their schedule, students are not required to interact at the same time (Kelly, 2012; Palsole \& Awalt, 2008; Parrish et al., 2021; Samuel \& Hinson, 2010), and most of delivered courses and experiences to adapt collaborative practices to the e-learning modality have been developed by incorporating asynchronous moments (Avery Gomez et al., 2010; Cabrera et al., 2017; Norman, 2020; Samuel \& Hinson, 2010; Silva et al., 2021). On the other hand, in synchronous learning, participants access course materials and lectures live; thus, they are required to interact at the same time, but fully 
synchronous e-learning classes are not, until now, frequent (Huffman et al., 2005; Martin et al., 2012; Norman, 2020; Silva et al., 2021; Wang \& Chen, 2007). Therefore, in this study, we selected the synchronous modality as the way to deliver the e-learning classes.

In the GCC countries, internet penetration rates are among the highest globally (Reseach \& Markets, 2017). In particular, Kuwait announced its national e-learning strategy in 2008 to keep pace with the rapid global technological developments and transform its educational system into the learning pedagogies of the twenty-first century (Al-Sharhan, 2018). Nevertheless, the public and private educational stakeholders who were implied on implementing the plan realized that to achieve a successful e-learning education system, it was necessary to orchestrate many variables, including different technological, pedagogical, cultural, and social components (Al-Fadhli, 2008; Al-Sharhan, 2018). It is challenging for STEM educators within eastern countries, particularly in the GCC region, to adequately address technology in their classes [68]. Moreover, cultural and social aspects are other crucial issues related to using technology in education within these countries (Almasri, 2022; Al-Sharhan, 2018). Thus, to correctly address these kinds of issues, the need arises for a comprehensive study on how e-learning, gender, gender-grouping, and collaborative learning affect undergraduate students' attitude and achievement in biology in the GCC conservative gender-segregated countries.

Impact of gender and gender-grouping within an e-learning environment There is evidence for gender-dependent patterns in e-learning collaborative settings (Burhanuddin et al., 2020). For instance, Zhan et al., 2015a, b) found that gender grouping mainly influenced students attitudes; while males preferred mixed-gender grouping, females felt more positive within single-gender and gender-minority groups (Zhan et al., 2015b). In addition, they found no significant difference for individual learning achievements in female students in single- and mix-gender grouping interventions; however, males performed significantly higher in mixed-gender groups than in single-gender groups. (Zhan et al., 2015b). In contraposition, Song et al. (2015) found that gender composition impacted group achievement; single-gender female groups were more productive than single-gender male groups, and female students showed a more collaborative behavior (Song et al., 2015). It was demonstrated that socio-cultural context could also affect the implementation of e-learning settings (Al-Sharhan, 2018; Karafyllis, 2015b).

With all social and cultural restrictions in GCC countries, e-learning environments could help overcome these limitations by providing alternate means of interaction in which students do not need to interact face-to-face (Graham \& Misanchuk, 2004; Stump, Husman, et al., 2011). In addition, evidence showed that interaction in the virtual world helped students be more expressive, analytical, and independent individuals, improving their confidence levels (Lansari et al., 2007; Tubaishat et al., 2006). Another study carried out in Kuwait found evidence that technology allowed students to overcome the socio-cultural barrier; especially female students were more active in the e-learning environment, demonstrating ability and willingness to collaborate with the instructor and other peers, which would not have been possible in the in-classroom setting (Al-Fadhli and media 2008; Al-Fadhli, 2009). Gaining 
this knowledge will allow GCC countries' stakeholders to formulate the best evaluation of the quality and effectiveness of pedagogies to design and conduct biology courses for each learner. To account for the gap in the literature, we carried a comprehensive study that aimed to compare female and male students' attitudes and achievements within different settings determined by learning modalities (e-learning and in-classroom), learning pedagogies (collaborative and traditional), and gender groupings (single-gender and mix-gender), in an attempt to determine which are the best pedagogies for undergraduate biology students.

\section{Theoretical framework, research questions and hypotheses}

\subsection{Theoretical framework}

This study was grounded on the ideas and epistemological bases of Keller's Motivational Theory (ARCS Model) and Vygotsky's Socio-cultural Theory. This framework allowed us to evaluate how gender and gender-grouping factors affected students' attitudes and achievement when engaged in twelve different learning settings designed according to traditional collaborative pedagogies and in-classroom and e-learning instructional modalities. In particular, Vygotsky's ideas helped us address the complexity of the socio-cultural context in which the research took place that is characterized by a conservative and gender-segregated educational system. An overview of the study's design with the twelve settings and its relations with the theories is presented in Fig. 1; the Socio-culturalism Theory encompasses the overall research, and the Motivational Theory is a key element that allowed us to evaluate the effect of the different variables on student's attitudes, what might ultimately affect their achievement in biology.

\subsection{Research questions}

The study attempted to answer the following major research question: in a conservative culture characterized by a gender-segregated educational system, which is the most conducive learning environment (e-learning versus in-classroom), educational pedagogy (CL versus TL), and gender grouping (single-gender versus mix-gender) to promote female and male students with a more positive attitude and higher achievement in a biology course?

To be able to answer the major question, it was necessary to examine numerous sub-questions, as follows:

1- Is there any difference between female and male students' learning attitudes and achievement in biology implementing e-learning single-gender collaborative classes? 


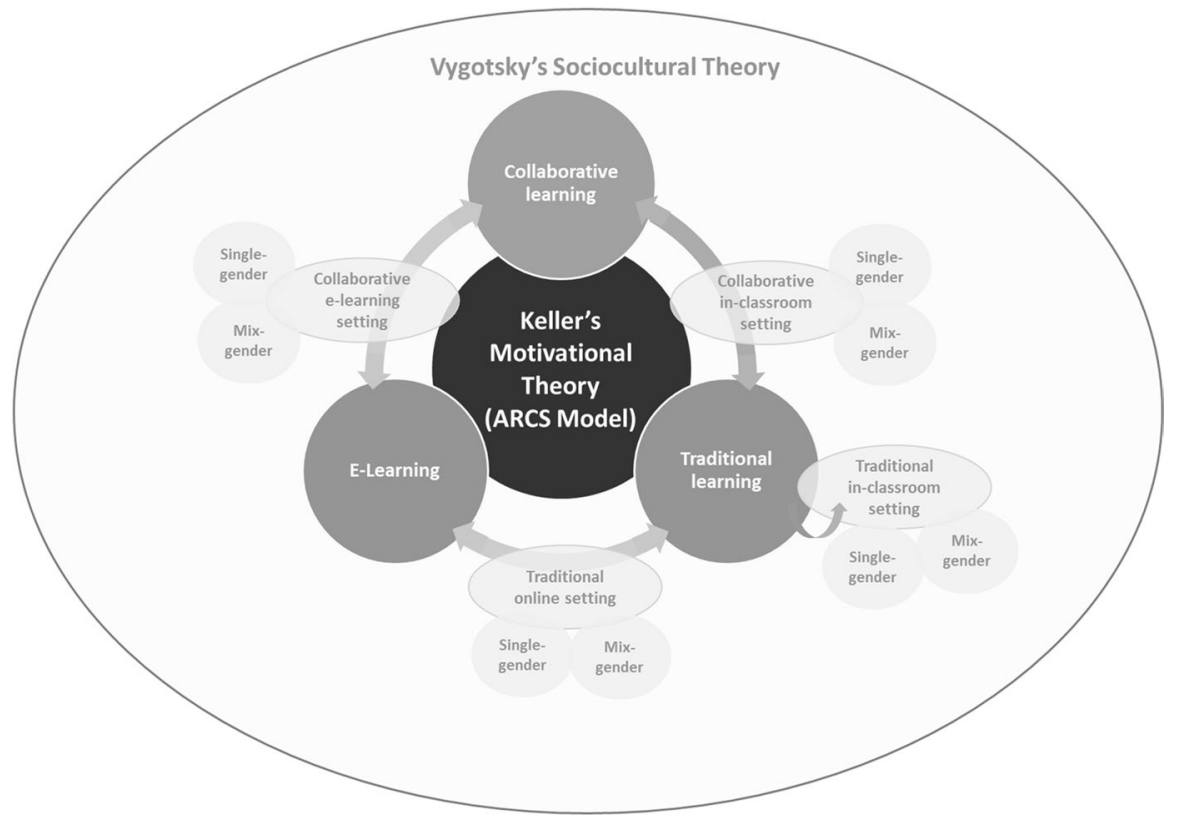

Fig. 1 Schematic representation of the learning settings and the theories on which the study is grounded. The Sociocultural Theory is at the center of the scheme because the effect of gender on students' attitudes and achievements was assessed within all the learning settings. The Motivational Theory (or ARCS Model) encompassed all the settings because students' motivation is a key element that defines their attitudes and might affect achievement within the different settings of the study, according to their gender and gender-groupings and learning pedagogies and modalities

2- Is there any difference between female and male students' learning attitudes and achievement in biology implementing e-learning single-gender traditional classes?

3- Is there any difference between female and male students' learning attitudes and achievement in biology implementing e-learning mix-gender collaborative classes?

4- Is there any difference between female and male students' learning attitudes and achievement in biology implementing e-learning mix-gender traditional classes?

5- Is there any difference between female and male students' learning attitudes and achievement in biology implementing in-classroom single-gender collaborative classes?

6- Is there any difference between female and male students' learning attitudes and achievement in biology implementing in-classroom single-gender traditional classes?

7- Is there any difference between female and male students' learning attitudes and achievement in biology implementing in-classroom mix-gender collaborative classes? 
8- Is there any difference between female and male students' learning attitudes and achievement in biology implementing in-classroom mix-gender traditional classes?

\subsection{Hypotheses}

Based on the research sub-questions, the following hypotheses were advanced considering the socio-cultural context according to the available evidence from the literature. In Fig. 2, we presented a scheme in which the eight hypotheses of the research were represented and related to the dependent variables of overall attitude and achievement assessed.

Hypothesis 1: In e-learning single-gender collaborative classes (EL-SG-CL), female students demonstrated more positive learning attitudes and higher biology achievement than male students. (H1: F $>$ M in EL-SG-CL)

Hypothesis 2: In e-learning single-gender traditional classes (EL-SG-TL), female students demonstrated more positive learning attitudes and higher biology achievement than male students. (H2: $\mathrm{F}>\mathrm{M}$ in EL-SG-TL)

Hypothesis 3: In e-learning mix-gender collaborative classes (EL-MG-CL), male students demonstrated more positive learning attitudes and higher biology achievement than female students. (H3: $\mathrm{M}>\mathrm{F}$ in EL-MG-CL).

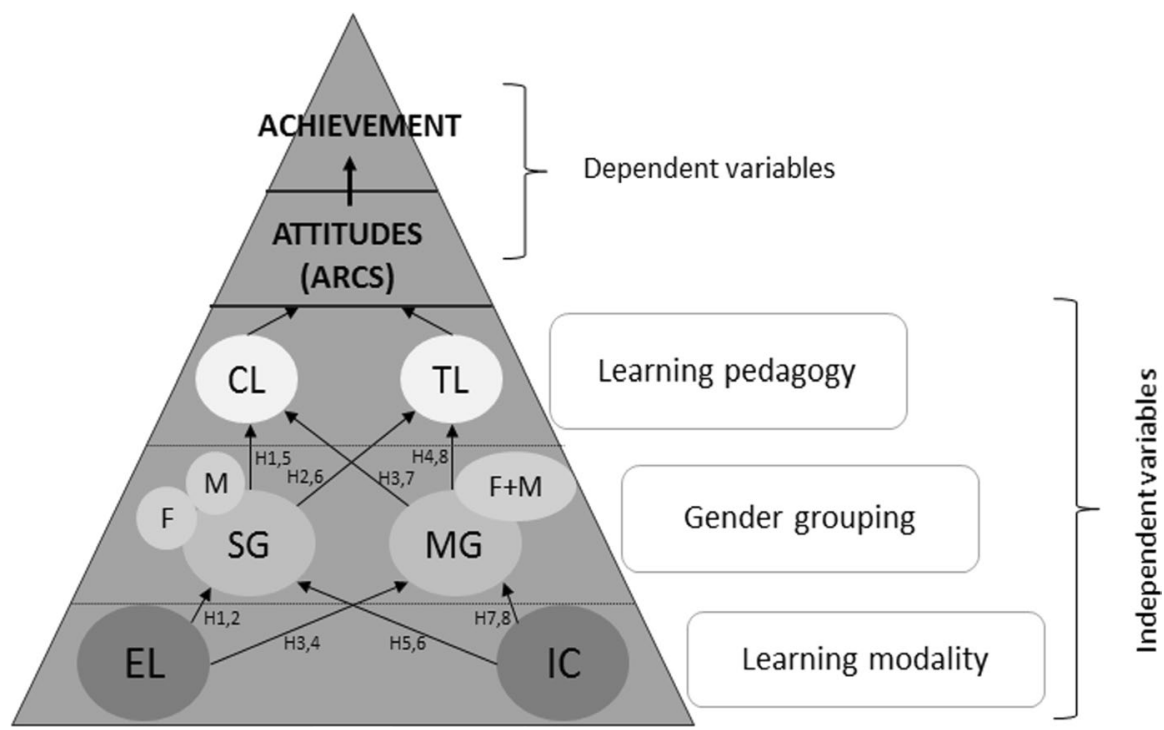

Fig. 2 Pyramidal representation of the eight hypotheses of the study. In the base, we represented the variable of learnings modalities (e-learning: EL and in-classroom: IC); in the next segment up the pyramid were represented the gender grouping (single-gender: SG and mix-gender: MG) and gender (female: F and male: M) variables; followed up the learning pedagogy variable (collaborative learning: CL and traditional learning: TL); and at the top of the pyramid were represented the dependent variables assessed in the study, which are overall attitude and achievement in biology 
Hypothesis 4: In e-learning mix-gender traditional classes (EL-MG-TL), female and male students demonstrated similar learning attitudes and higher achievements in biology. (H4: $\mathrm{F}=\mathrm{M}$ in EL-MG-TL).

Hypothesis 5: In in-classroom single-gender collaborative classes (IC-SG-CL), female students demonstrated more positive learning attitudes and higher biology achievement than male students. (H5: F $>$ M in IC-SG-CL)

Hypothesis 6: In in-classroom single-gender traditional classes (IC-SG-TL), female students demonstrated more positive learning attitudes and higher biology achievement than male students. (H6: F $>\mathrm{M}$ in IC-SG-TL)

Hypothesis 7: In in-classroom mix-gender collaborative classes (IC-MG-CL), male students demonstrated more positive learning attitudes and higher biology achievement than female students. (H7: M $>$ F in IC-MG-CL).

Hypothesis 8: In in-classroom mix-gender traditional classes (IC-MG-TL), female and male students demonstrated similar learning attitudes and higher achievement in biology. (H8: $\mathrm{F}=\mathrm{M}$ in IC-MG-TL).

\section{Methodology}

\subsection{Participants}

The participants were 1375 undergraduate students enrolled in a biology course as an elective subject in a public university in Kuwait. They were freshmen aged from 18 to 22 years old. Among them, 682 were female, and 693 were male. The students were chosen using a simple random sample method from the program administrative records (Almasri et al., 2021), ensuring that every student in the population could be selected for any learning setting in the study.

\subsection{Ethics statement}

The research ethics committee at a university in the United Kingdom and a public university in Kuwait approved the study; the researchers ensured that there would be no ethical objections to the study. The present study followed the British Educational Research Association (BERA, 2014). The participants signed a consent form. Students were provided with a study participation form, they could ask any question regarding the research, and in case of agreement, they signed it to participate in the study. The form followed national personal data protection regulations to ensure participants' anonymity and no recriminations irrespective of their answers.

\subsection{Learning settings}

The 1375 undergraduate students were randomly assigned to one of the following twelve settings: E-learning — single-gender-traditional learning (EL-SG-TL): female or male students were individually assigned into a separate e-learning class without interaction among them (Fig. 3C, D). E-learning-mix-gender-traditional 

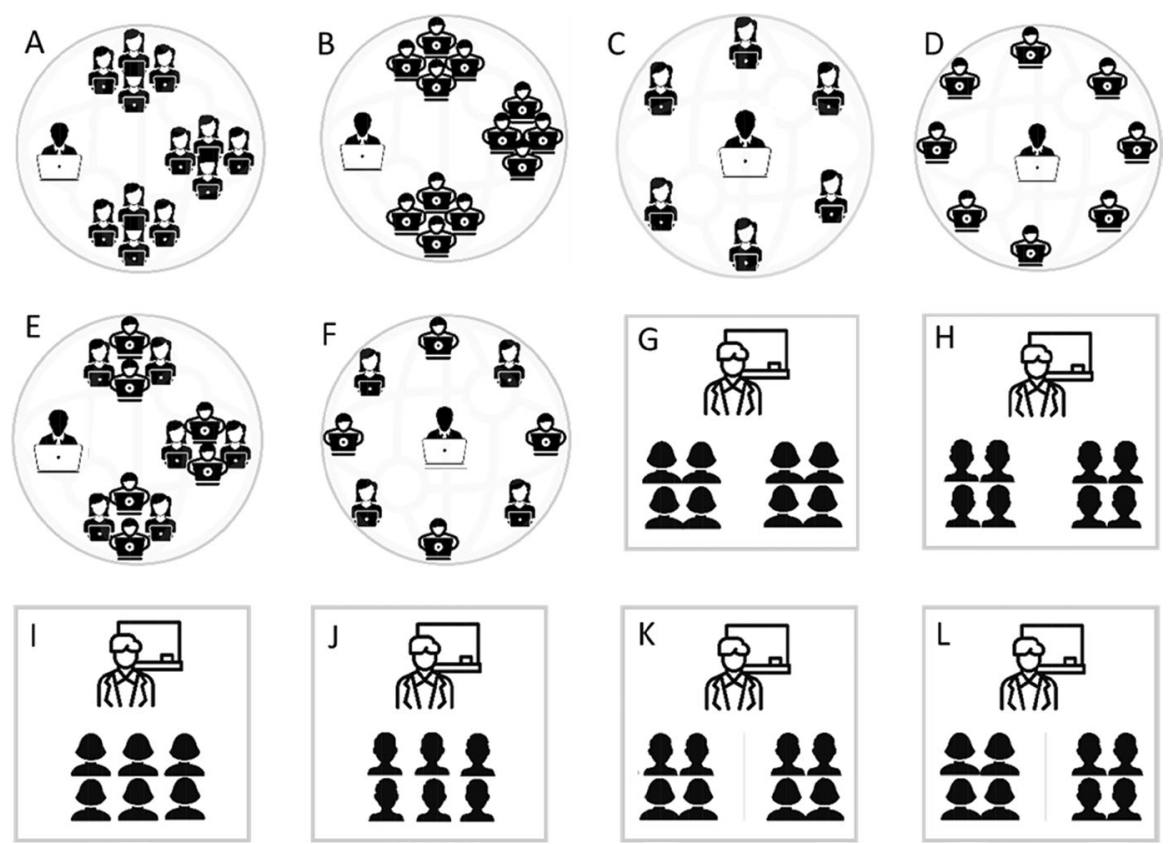

Fig. 3 Representation of the twelve learning settings of the study. A) Female students within e-learning single-gender collaborative learning setting. B) Male students within e-learning single-gender collaborative learning setting. C) Female students within e-learning single-gender traditional learning setting. D) Male students within e-learning single-gender traditional learning setting. E) Female and male students within e-learning mix-gender collaborative learning setting. F) Female and male students within e-learning mix-gender traditional learning settings. G) Female students within in-classroom single-gender collaborative learning setting. H) Male students within in-classroom single-gender collaborative learning setting. I) Female students within in-classroom single-gender traditional learning setting. J) Male students within in-classroom single-gender traditional learning setting. K) Female and male students within in-classroom mix-gender collaborative learning settings. L) Female and male students within in-classroom mix-gender traditional learning setting

learning (EL-MG-TL): female or male students were individually assigned within the same e-learning classroom without interaction among them (Fig. 3F). E-learning - single-gender-collaborative learning (EL-SG-CL): female or male students were assigned into 4-members single-gender groups (4 female) or (4 male) in separate e-learning interaction group classes (Figs. 3A, B). E-learning-mixgender-collaborative learning (EL-MG-CL): female and male students were assigned into 4-members groups ( 2 female +2 male) in the same e-learning classroom (Fig. 3E); students interact using camera and microphone in their chat meeting room; besides, they had access to the class general chat. In-classroom-singlegender-traditional learning (IC-SG-TL): female or male students were assigned into a separate classroom without interaction among them (Fig. 3I, J). In the inclassroom-mix-gender-traditional learning (IC-MG-TL), female and male students were assigned to the classroom, but they stood separately, with females on one side and males on the opposite side with no interaction between students (Fig. 3L). 
In-classroom-single-gender-collaborative learning (IC-SG-CL): female or male students were assigned into 4-members groups (4 female) or (4 male) in a separate classroom interacting with each other (Fig. 3G, H). Finally, In-classroom-mix-gender-collaborative learning (IC-MG-CL): female and male students were assigned into 4-members groups, 2 female +2 male students interactions were face to face (Fig. 3K). Steps were taken to ensure as much equivalence among treatment groups as possible (i.e., the same curriculum, written and audio-visual resources, lectures, exams, and expected learning outcomes assessment).

\subsection{Measures}

\subsubsection{Dependent and independent variables}

Dependent variables for the study included: (1) overall attitude towards biology, with the categories of Attention, Confidence, Relevance and Satisfaction, according to the ARCS Model (Keller, 1984, 2010); and achievement scored as (2) overall achievement, (3) pre-exam and (4) post-exam. Independent variables included: (1) gender (F, M); (2) gender grouping (SG groups with 4F, $4 \mathrm{M}$ and MG balancedgroups with $2 \mathrm{~F}+2 \mathrm{M}$ ); (3) learning environment modality (EL and IC); (4) learning pedagogy (CL and TL).

\subsubsection{The correlation coefficient}

To assess the relationship between two variables, the correlation coefficient $(r)$ was utilized for the scores of overall attitude and overall achievement and between posttest and overall achievement scores. Theoretically, the correlation coefficient can assume any value in the interval between +1 and -1 , including the end values +1 or -1 (Ratner, 2009). As much as $r$ is closer to +1 or -1 , it indicates a perfect positive or negative linear relationship, respectively. There is no linear relationship when the correlation coefficient is 0 . A mild positive (or negative) linear connection exists between 0 and 0.3 ( 0 and 0.3 ); a moderate positive (or negative) linear relationship exists between 0.3 and 0.7 (0.3 and 0.7 ); and a strong positive (or negative) linear relationship exists between 0.7 and 1.0 (0.7 and 1.0) (Ratner, 2009).

\subsubsection{Effect size: Cohen's d coefficient}

To provide a standardized measure of an effect's strength or magnitude, we measured the effect size through Cohen's $d$ coefficient. The $d$ value gave us a standardized way of assessing the magnitude of the effect on students' overall attitudes and overall achievement among the different settings of the study. Standardization is essential because it ensures that each effect size is represented in the same way, i.e., in a consistent manner, regardless of the outcome construct, measurement method, or analysis method (Lipsey et al., 2012). To define the kind of effect observed, we followed Cohen's categories of small (0.20), medium (0.50), and large (0.80) effects. The effect size had a positive value when the intervention group (e-learning, EL) did 
more positive on the outcome measure than the control group (in-classroom, IC) and a negative sign when it did worse (Lipsey et al., 2012). In practice, we calculated the effect size if we previously found that the effect was statistically significant.

\subsubsection{Intervention effect}

The intervention effect was measured between pre-test and post-test and pro-test and total class achievement scores to reveal the result and the patterns of improvement or decline that characterized the different interventions proposed in the study and control groups. The rate of difference between the intervention and control groups' post-test differences and the control group's pre-post change were used to compute the differential change for the intervention and control groups (difference between the control group's post-test and pre-test) as described in a previous study (Lipsey et al., 2012). For each setting, we calculated the differential change of the experimental e-learning intervention against in-classroom control for the female or male students' population within each of the eight arrangements proposed for the study.

\subsubsection{Students' learning attitudes}

Course Interest Survey (Barnett \& Francis, 2012; Keller, 1984, 2010) was used to measure how motivated were the undergraduate students in the context of the e-learning and in-classroom instructional settings displayed in the study. The survey has 34 items divided into four categories: Attention ( 8 items), Relevance ( 9 items), Confidence ( 8 items), and Satisfaction (9 items). More details about each category are found in (Keller, 2010). Responses to the items were in the form of a five-point Likert scale, with the following values: $1=$ Not true; $2=$ Slightly true; $3=$ Moderately true; $4=$ Mostly true; and 5=Very true. The overall attitude score was calculated as the sum of the four categories. Cronbach's alpha coefficient for the CIS is 0.95 . Alpha coefficient values for the categories are 0.84 for Attention, 0.84 for Relevance, 0.81 for Confidence, and 0.88 for Satisfaction (Keller, 2010).

\subsubsection{Students' learning achievement}

Overall achievement Students' overall learning achievement was measured by the sum of scores among the final exam and all the usual exams delivered during the semester. The final exam consisted of highly similar critical thinking questions similar to the pre-and post-test, but the total exam general questions counted $40 \%$. The regular exams were completed individually by each student in each class.

Pre-test and post-test Students were asked to take a pre-test at the start of the semester to assess their biology knowledge. The pre-test consisted of a 50-item exam; all the items were randomly selected from an exam bank of a published concept inventory (Kalas et al., 2013). Among the 50 items, 30 were multiple-choice questions (MCQs) of 1 mark each, and 10 were short answer questions (SAQs) of 2 marks each. The exam consisted of general questions about knowledge in biology (which sum $60 \%$ of the total exam), questions covering more specific knowledge, 
and critical thinking questions that challenged students to perform a deeper analysis to get an answer. Responding to the critical thinking questions led to the activation of cognitive processes, unlike the simple memorization and repetition of details (Barnett \& Francis, 2012; Dori, 1995; Kalas et al., 2013). Students were asked to take a post-test one week before the semester ended. The 50-items of the posttest were the same as the pre-test. This exam aimed to examine students' acquired knowledge in biology during the semester to be compared towards students' preacquired knowledge given by the pre-test.

\subsection{Course and instructional materials}

The biology course taught students to sort out biological questions applying the same curriculum under e-learning and in-classroom settings. It is essential to highlight that the university's educational structure, curricula, methods, and standards are based on the American model of higher education (Al-Khaldi 2007b; Singera et al., 2014). Topics covered during the semester included cell biology, biochemistry, anatomy, and physiology. Students also received guidelines for assignments and additional written or audio-visual resources. The intensity of these activities became more challenging every 2 or 3 classes because it was found that this practice would lead students to develop more creative thinking skills to solve them (Scager et al., 2016; Stump, Hilpert, et al., 2011). The same instructor covered the curriculum topics through identical lectures and delivered the additional learning resources to all students.

\subsection{Procedures}

Three classes were held every week for one hour during a four-month semester. Students from biology were assigned to e-learning or in-classroom learning modalities within CL and TL environments at random selections. To test our hypotheses, we applied the interventions described in Fig. 3 for the following sections.

\subsubsection{E-learning traditional settings}

Students joined the classes by Microsoft Teams and had access to the course materials posted on moodle platform using their computer devices (Microsoft Teams 2016). Students in the e-learning traditional single-gender setting (Fig. 3C \& D) and those in the traditional mix-gender setting (Fig. 3F) participated individually, and no interactions were between classmates. In addition, if students liked to participate in TL e-learning classes, they could use their microphones and cameras by turning them on or off. All lectures were recorded and saved for students' reference. Students logged in to the moodle platform using their login information to access the posted homework and activities. The pre-test, post-test, and exams were posted on moodle and students had their camera and microphone open. Students were required to complete each test for the time given; after the time was up, the test was submitted automatically, or the student could submit 
their work at any point during the time limit. Assignments and activities were aligned with the questions of the upcoming usual exams, as suggested by many authors (Armstrong, 2011; Mitchell et al., 2011).

E-learning collaborative learning pedagogy Students within the e-learning collaborative settings were assigned randomly to join single-gender or mix-gender groups during the semester (Le et al., 2017; Márquez et al., 2017b; Thirteen Edition Online). The instructor used the random number generator function in Microsoft Excel to assign students to small groups of 4 students into the CL single-gender (Fig. 3A \& B) and CL mix-gender (Fig. 3E) settings. Evidence suggests that smaller groups work more effectively than larger groups (Cen et al., 2016a). Moreover, they were stable groups because this social cohesion creates a more motivated, friendly, and effective teamwork environment among students (Slavin, 1996b). The CL classes were implemented through the Jigsaw method (Márquez et al., 2017a; Takeda et al., 2017; Tekbiyık, 2015), which focuses on group discussions of a given activity (Iborra et al., 2009; Tekbıyık, 2015). Each group had their chat meeting room; besides, they had access to the class general chat. Students within a group were required to prepare the lecture topic, discuss it, and answer each other's questions or doubts; before the class, they divided the material among the members so each one could explain a specific part of the topic to the rest of the group participants constantly interacting within the e-learning environment. Students had a schedule with the topics to cover weekly along with the biology classes (Tekbiyık, 2015). Students in the e-learning groups had their microphones and cameras open, and their discussions were virtual or using the Teams chat; students had the freedom to mute their microphones (Thomas \& Setiaji, 2014). The instructor posted worksheet activities related to the topic on moodle, students discussed and solved them, and the instructor was available for the group during the class. These activities could comprise either a real-life scenario related to the topic at hand, fill in the blanks, or true or false questions. The groups had around three activities per lecture that held almost $70 \%$ of the 60 min-class. Finally, the instructor summarized the topics, solved the activities with the students, and wrap-up the lecture.

Traditional learning pedagogy in-classroom Students in the TL classroom sat individually in the TL single-gender setting (Fig. 3I \& J) with male and female students in separate classrooms; in the TL mix-gender setting, males sat opposite to the females and there was no interaction between students (Fig. $3 \mathrm{G} \& \mathrm{H}$ ). The instructor organized and controlled the activities of the entire class, guided every step of the process, defined the questions and procedures of investigation, attempting to guide students, promoted thinking, and provoked curiosity (Dawkins et al., 2017; Thorne, 2003). Students studied the lecture topic posing and answering problems following the instructor's directives without interaction among them (Thorne, 2003).

Collaborative learning pedagogy in-classroom In the collaborative learning (CL) sections, the instructor used the random number generator function in Microsoft excel to assign students to groups of four students. Students were asked to sit with 
the same groups in specific areas for the rest of the course. Following such procedure falls under the jigsaw method implementation in a collaborative learning class, where the focus is on the group discussion in an activity which is highly recommended when a subject to be taught consists of independent portions (Indriwati et al., 2019; Márquez et al., 2017b). Students interacted face-to-face in CL, both in mix-gender settings where female and male students ( 2 female +2 male) were in the same group (Fig. 3K) and in single-gender settings where the female (4F) or male (4 M) groups interacted in a separate classroom (Fig. 3G \& H).

\subsection{Statistical analyses}

Quantitative data were collected from the attitude survey and the pre-, post-, and final exams (overall achievement) and analyzed using the SPSS 27. Four-way ANOVA tests were used to analyze the mean scores and interaction effects between all the factors of the study, namely: gender (F, M), learning modalities (EL, IC), learning pedagogies (CL, TL), and gender-grouping (SG, MG), for all the dependent variables, namely: overall attitude (and its four categories: attention, relevance, confidence, satisfaction) and overall achievement. The mean scores and interaction effects were analyzed using two-way ANOVA testing between gender (F, M) and learning pedagogies (CL, TL), with EL or IC and SG or MG as fixed factors for all the dependent variables mentioned above previously for the 4-way ANOVA. To reach a set of conclusions according to the main hypotheses $(\mathrm{H} 1-\mathrm{H} 8)$, eight one-way ANOVAs were carried out four each of the dependent variables mentioned above to compare the effects of gender factor (F vs M) with EL or IC, SG or MG, and CL or TL as fixed factors. T-tests for independent samples were carried out to determine differences among female and male students' populations within the different settings of the study. For all the ANOVAs and T-tests, a 95\% significance level was used.

\section{Results}

This study sought to compare students' attitudes and achievements between e-learning vs. in-classroom instructional modalities in an undergraduate biology course, considering three levels: learning pedagogy (collaborative and traditional), gender-grouping (single-gender and mix-gender), and students' gender (female and male). The interaction among the four factors of the study was assessed (instructional modality (EL, IC) x gender $(\mathrm{F}, \mathrm{M}) \mathrm{x}$ learning pedagogy $(\mathrm{CL}, \mathrm{TL}) \mathrm{x}$ gender grouping (SG, MG)) through a four-way ANOVA test, and found it was statistically significant for attitude $\left(\mathrm{F}(1,1359)=30.93, \mathrm{p}<0.000, \mathrm{R}^{2}=0.425\right)$ and achievement $\left(\mathrm{F}(1,1359)=40.00, \mathrm{p}<0.000, \mathrm{R}^{2}=0.626\right)$. Whereas we found that two of the triple interactions were significant for each of the dependent variables mentioned, and they were not the same for both. For attitude, the statistically significant interactions were: instructional modality (EL, IC) x gender $(\mathrm{F}, \mathrm{M}) \mathrm{x}$ learning pedagogy (CL, TL) $\left(\mathrm{F}(1,1359)=24.29, \mathrm{p}<0.000, \mathrm{R}^{2}=0.425\right)$ and gender grouping $(\mathrm{SG}, \mathrm{MG}) \mathrm{x}$ gender 
$(\mathrm{F}, \mathrm{M}) \mathrm{x}$ learning pedagogy $(\mathrm{CL}, \mathrm{TL})\left(\mathrm{F}(1,1359)=41.83, \mathrm{p}<0.000, \mathrm{R}^{2}=0.425\right)$. For achievement, the statistically significant interactions were: instructional modality $(\mathrm{EL}, \mathrm{IC}) \mathrm{x}$ gender $(\mathrm{F}, \mathrm{M}) \mathrm{x}$ gender grouping $(\mathrm{SG}, \mathrm{MG})(\mathrm{F}(1,1359)=167.92$, $\left.\mathrm{p}<0.000, \mathrm{R}^{2}=0.626\right)$ and learning pedagogy $(\mathrm{CL}, \mathrm{TL}) \times$ gender $(\mathrm{F}, \mathrm{M}) \times$ gender grouping $(\mathrm{SG}, \mathrm{MG})\left(\mathrm{F}(1,1359)=63.79, \mathrm{p}<0.000, \mathrm{R}^{2}=0.626\right)$. Hereafter, we organized the results section between two main categories: e-learning and in-classroom instructional modalities.

\subsection{E-learning modality}

This section was organized into sub-categories, according to hypotheses 1 to 4 . To test each hypothesis, we conducted a one-way ANOVA test to compare female and male students' overall attitude —and its four categories (attention, relevance, confidence, satisfaction)_, achievement, pre-test, and post-test within each e-learning setting. Then, we compared the overall attitudes and achievement within samegender students' through T-tests, one for females and the other for male students. Finally, we evaluated the significance of the interaction between gender (female, F / male, M) x learning pedagogy (collaborative, CL / traditional, TL) with e-learning (EL) and single-gender (SG) or mix-gender (MG) as the fixed levels of each factor. With this aim, we conducted two-way ANOVA tests.

In Table 1, we arranged the data according to hypotheses 1 to 4 to examine female and male students' overall attitude and the four sub-categories of the CIS; correlation scores between overall attitude and achievement were also provided. Table 2 arranged the data for female and male students' pre-test, post-test, and achievement; correlation scores between post-test and achievement were also provided.

\subsubsection{Hypotheses 1 to 4: e-learning single-gender and mix-gender grouping within collaborative and traditional pedagogies}

Attitudes towards e-learning biology Results supported hypothesis one (H1: F > M attitude in EL-SG-CL); female students demonstrated significantly more positive attitudes towards biology $(\mu=3.61, \mathrm{SD}=0.69)$ than male students $(\mu=3.20$, $\mathrm{SD}=0.60)$ in the EL-SG collaborative setting $(\mathrm{F}(1,177)=18.31, \mathrm{p}<0.000$, $\mathrm{R}^{2}=7.44$ ) (Table 1, Fig. 4A), with a medium effect between means (Cohen's $d=0.63)$. Results also supported hypothesis two $(\mathrm{H} 2: \mathrm{F}>\mathrm{M}$ attitude in EL-SG$\mathrm{TL})$; female students demonstrated significantly more positive attitudes $(\mu=3.40$, $\mathrm{SD}=0.66)$ than male students $(\mu=2.43, \mathrm{SD}=0.66)$ within the EL-SG traditional setting $\left(\mathrm{F}(1,174)=96.01, \mathrm{p}<0.000, \mathrm{R}^{2}=41.75\right)$ (Table 1 , Fig. 4A), with a large effect between means (Cohen's $d=1.47)$. In addition, hypothesis three (H3: M F attitude in EL-MG-CL) was supported since male students demonstrated significantly more positive overall attitude towards biology $(\mu=3.82, \mathrm{SD}=0.60)$ than female students $(\mu=3.00, \mathrm{SD}=0.58)$ in e-learning mix-gender collaborative groups $\left(\mathrm{F}(1,174)=86.78, \mathrm{p}<0.000, \mathrm{R}^{2}=29.85\right)$ (Table 1, Fig. 4B), with a large effect between means (Cohen's $d=1.39$ ). Finally, results supported hypothesis four as well (H4: $\mathrm{F}=\mathrm{M}$ attitude in EL-MG-TL) because students demonstrated similar overall 


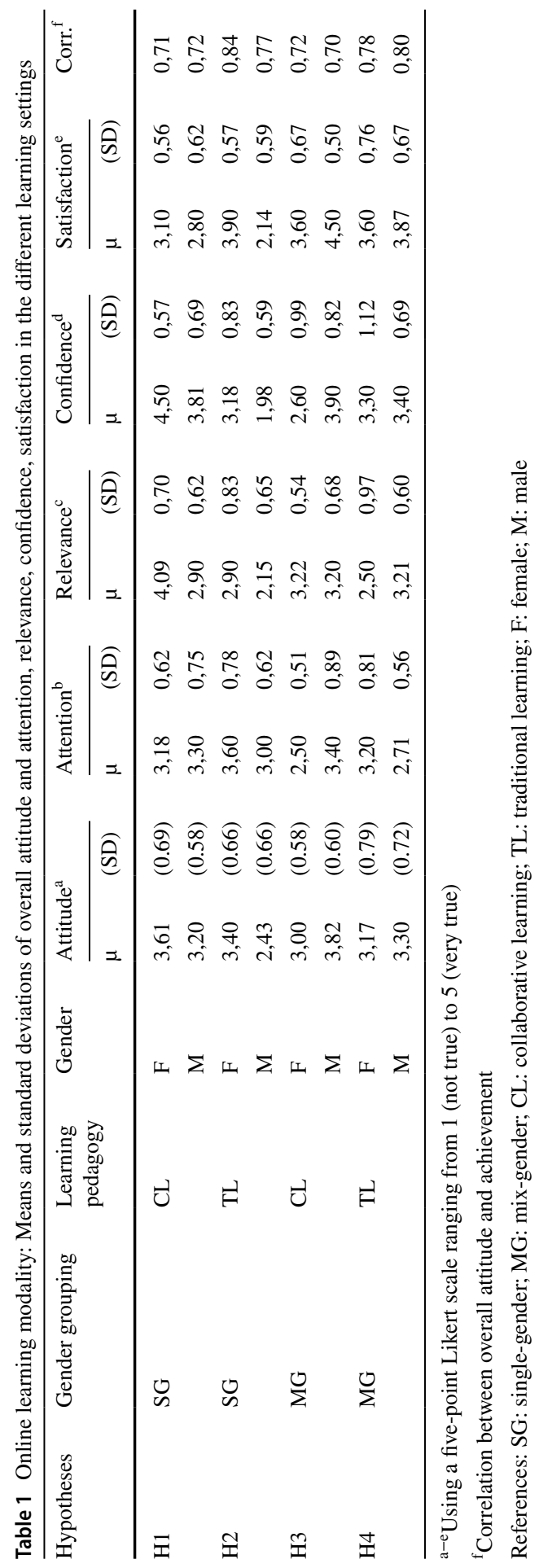




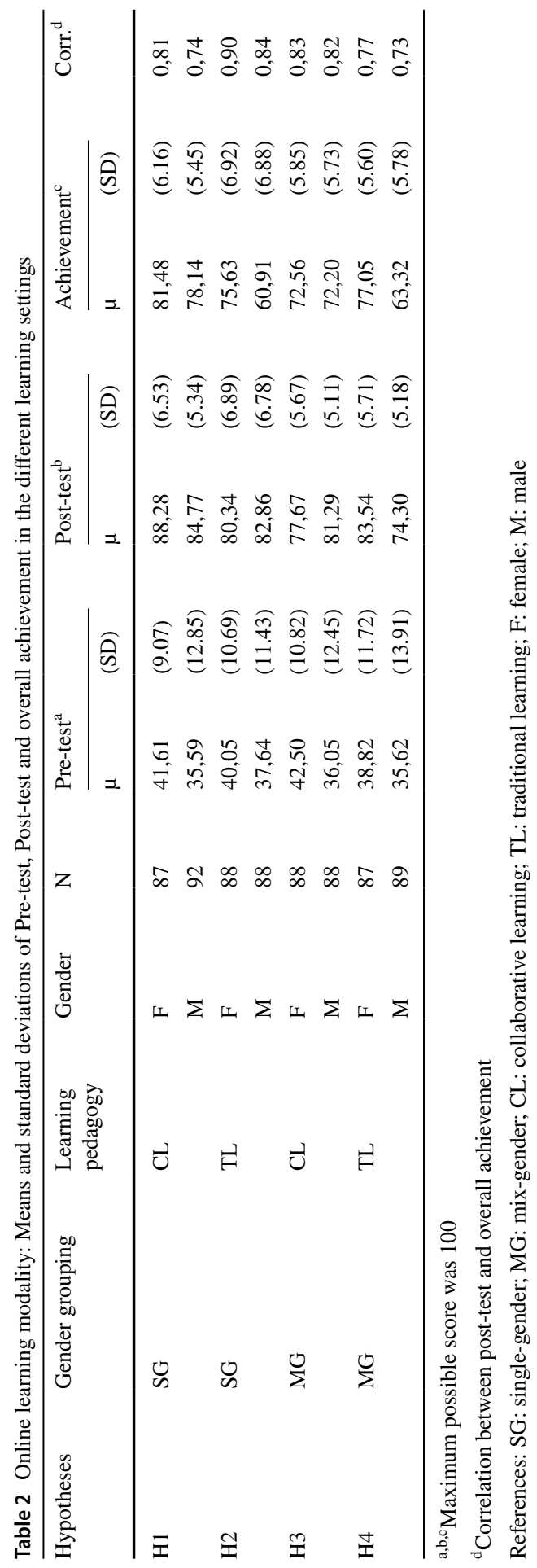




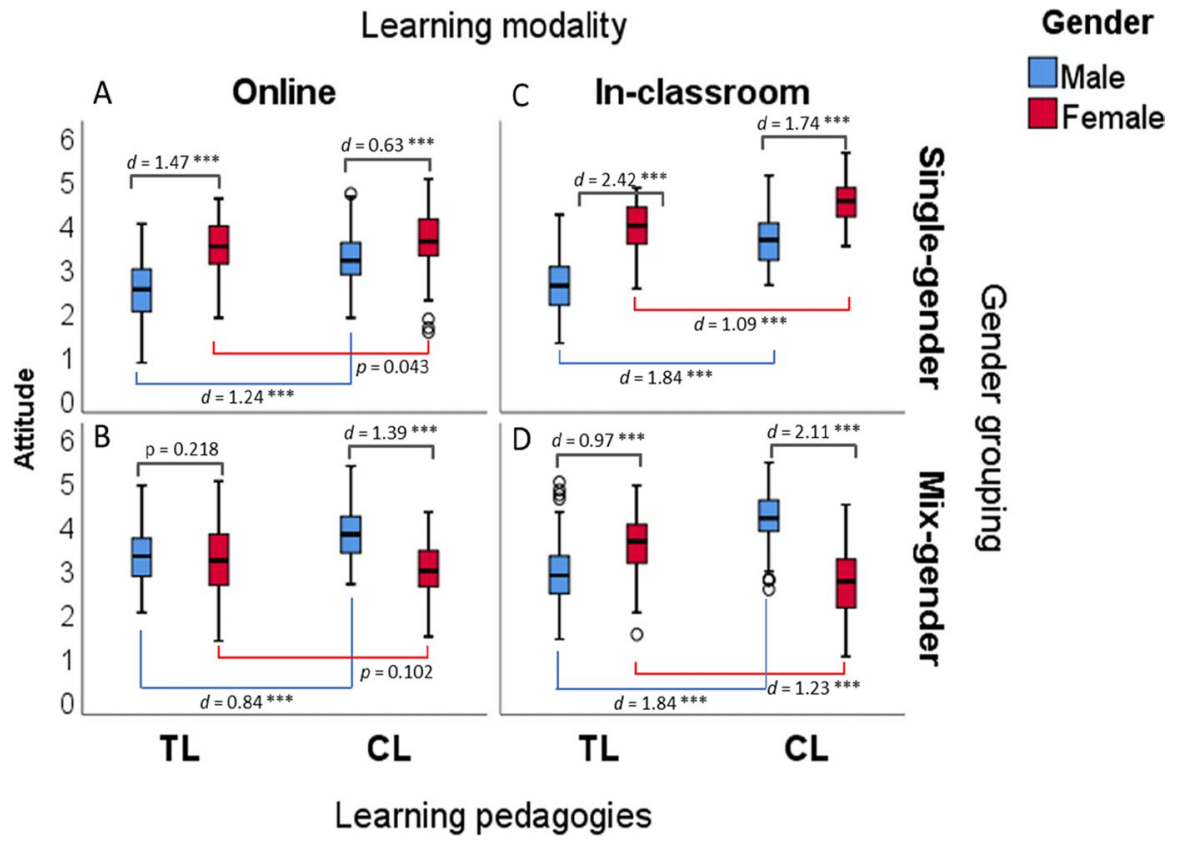

Fig. 4 Overall attitude comparisons between female and male students in the different settings of the study: A) e-learning single-gender; B) e-learning mix-gender; C) In-classroom single-gender; D) Inclassroom mix-gender. Standard deviation and Cohens $d$ coefficient were represented in each graph $(* * *=\mathrm{p}<0.000)$. The $p$-value was presented to indicate non-significance between groups. References: CL: collaborative learning; TL: traditional learning

attitude within e-learning mix-gender, traditional classes, with no significant differences between female $(\mu=3.17, \mathrm{SD}=0.79)$ and male $(\mu=3.31, \mathrm{SD}=0.64)$ students $(\mathrm{F}(1,174)=1.53, \mathrm{p}=0.218)($ Table 1, Fig. 4B).

Female students within e-learning single-gender collaborative groups $(\mu=3.61$, $\mathrm{SD}=0.69)$ scored similarly compared to those female students in e-learning single-gender traditional classes $(\mu=3.40, \mathrm{SD}=0.66)$, with no significant differences between means $(\mathrm{p}=0.043)$ (Fig. 4A). In contraposition, male students within e-learning single-gender collaborative groups $(\mu=3.20, \mathrm{SD}=0.58)$ demonstrated significantly higher overall attitude $(\mathrm{p}<000)$ than those male students in the traditional setting $(\mu=2.43, \mathrm{SD}=0.66$ ), with a large effect between means (Cohen's $d=1.24$ ) (Fig. 4A). Regarding the e-learning mix-gender collaborative setting, female students $(\mu=3.00, \mathrm{SD}=0.58)$ scored similarly compared to those female students within the traditional setting $(\mu=3.17, \mathrm{SD}=0.79)$, with no significant differences between means $(p=0.102)$ (Fig. 4B). However, in contraposition, male students within e-learning mix-gender collaborative groups $(\mu=3.82, \mathrm{SD}=0.60)$ demonstrated significantly higher overall attitude $(\mathrm{p}<0.000)$ than those in the traditional setting $(\mu=3.31, \mathrm{SD}=0.64)$, with a large effect between means (Cohen's $d=0.84$ ) (Fig. 4B). 
ARCS categories of attitude in e-learning

Female students experienced significantly higher relevance, confidence and satisfaction towards the biology course than male students in both the e-learning single-gender (EL-SG) collaborative and traditional settings, with the unique exception that females and male students experienced similar attention in the e-learning collaborative setting (Table 1, Fig. 5 A-D). In the EL-SG collaborative settings, for relevance $\mathrm{F}(1,177)=147.30, \mathrm{p}<0.000, \mathrm{R}^{2}=63.92$, for confidence $\mathrm{F}(1,177)=53.82$, $\mathrm{p}<0.000, \mathrm{R}^{2}=21.71$, and for satisfaction $\mathrm{F}(1,177)=11.33, \mathrm{p}<0.000, \mathrm{R}^{2}=3.99$. Whereas in the EL-SG traditional settings, for attention $(\mathrm{F}(1,174)=31.29, \mathrm{p}<0.000$, $\left.\mathrm{R}^{2}=15.64\right)$, for relevance $\mathrm{F}(1,174)=45.32, \mathrm{p}<0.000, \mathrm{R}^{2}=25.00$, for confidence $\mathrm{F}(1,174)=122.87, \mathrm{p}<0.000, \mathrm{R}^{2}=63.40$, and for satisfaction $\mathrm{F}(1,174)=402.23$, $\mathrm{p}<0.000, \mathrm{R}^{2}=136.81$.

In contraposition, in the e-learning mix-gender (EL-MG) collaborative setting, male students experienced significantly higher attention, confidence and satisfaction than female students, and scored also higher than females in relevance and satisfaction in the traditional setting (Table 1, Fig. 5 E-H). Female students only

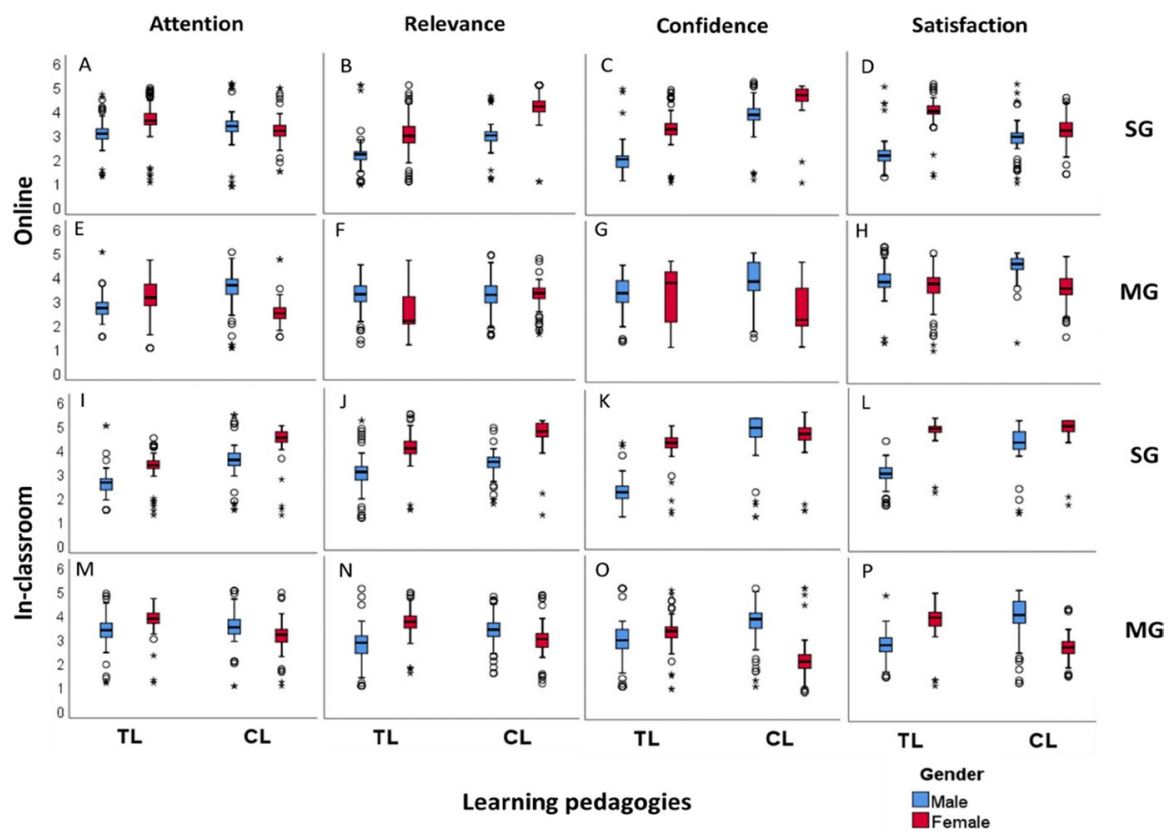

Fig. 5 Categories of attitude comparisons between female and male students in the different settings of the study. Attention, Relevance, Confidence and Satisfaction variables were represented for: A-D) e-learning single-gender; E-H) e-learning mix-gender; I-L) in-classroom single-gender; M-P) in-classroom mix-gender. Standard deviations were represented in each graph. References: CL: collaborative learning; TL: traditional learning; SG: single-gender; MG: mix-gender. Outliers values were represented with a circle and extreme values with an asterisk. We considered all data since they represent each student's responses to the Course Interest Survey 
experienced higher attention than male students in the traditional setting. In the EL-MG collaborative setting, for attention $\mathrm{F}(1,174)=68.79, \mathrm{p}<0.000, \mathrm{R}^{2}=35.95$, relevance $\mathrm{F}(1,172)=0.045, \mathrm{p}=0.83, \mathrm{R}^{2}=0.017$, for confidence $\mathrm{F}(1,174)=89.69$, $\mathrm{p}<0.000, \mathrm{R}^{2}=73.66$, and for satisfaction $\mathrm{F}(1,174)=101.47, \mathrm{p}<0.000, \mathrm{R}^{2}=35.36$. Whereas in the EL-MG traditional setting, for attention $\mathrm{F}(1,173)=21.58, \mathrm{p}<0.000$, $\mathrm{R}^{2}=10.36$, for relevance $\mathrm{F}(1,173)=33.95, \mathrm{p}<0.000, \mathrm{R}^{2}=22.01$, for confidence $\mathrm{F}(1,174)=0.46, \mathrm{p}=0.50, \mathrm{R}^{2}=0.40$, and for satisfaction $\mathrm{F}(1,171)=6.46, \mathrm{p}=0.012$, $\mathrm{R}^{2}=3.31$.

\section{Interaction effects in e-learning}

The interaction between gender $\mathrm{x}$ learning pedagogy for e-learning and single-gender as fixed levels, significantly affected the variable of overall attitude $\left(\mathrm{F}(1,351)=16.91, \mathrm{p}<0.000, \mathrm{R}^{2}=0.32\right)$ (Fig. 6A), and the categories of attention $\left(\mathrm{F}(1,351)=23.58, \mathrm{p}<0.000, \mathrm{R}^{2}=0.09\right)$, relevance $(\mathrm{F}(1,351)=8.79, \mathrm{p}=0.003$, $\left.\mathrm{R}^{2}=0.49\right)$, confidence $\left(\mathrm{F}(1,351)=12.25, \mathrm{p}=0.001, \mathrm{R}^{2}=0.65\right)$, and satisfaction $\left(\mathrm{F}(1,351)=137.36, \mathrm{p}<0.000, \mathrm{R}^{2}=0.54\right)$. The interaction between gender $\mathrm{x}$ learning

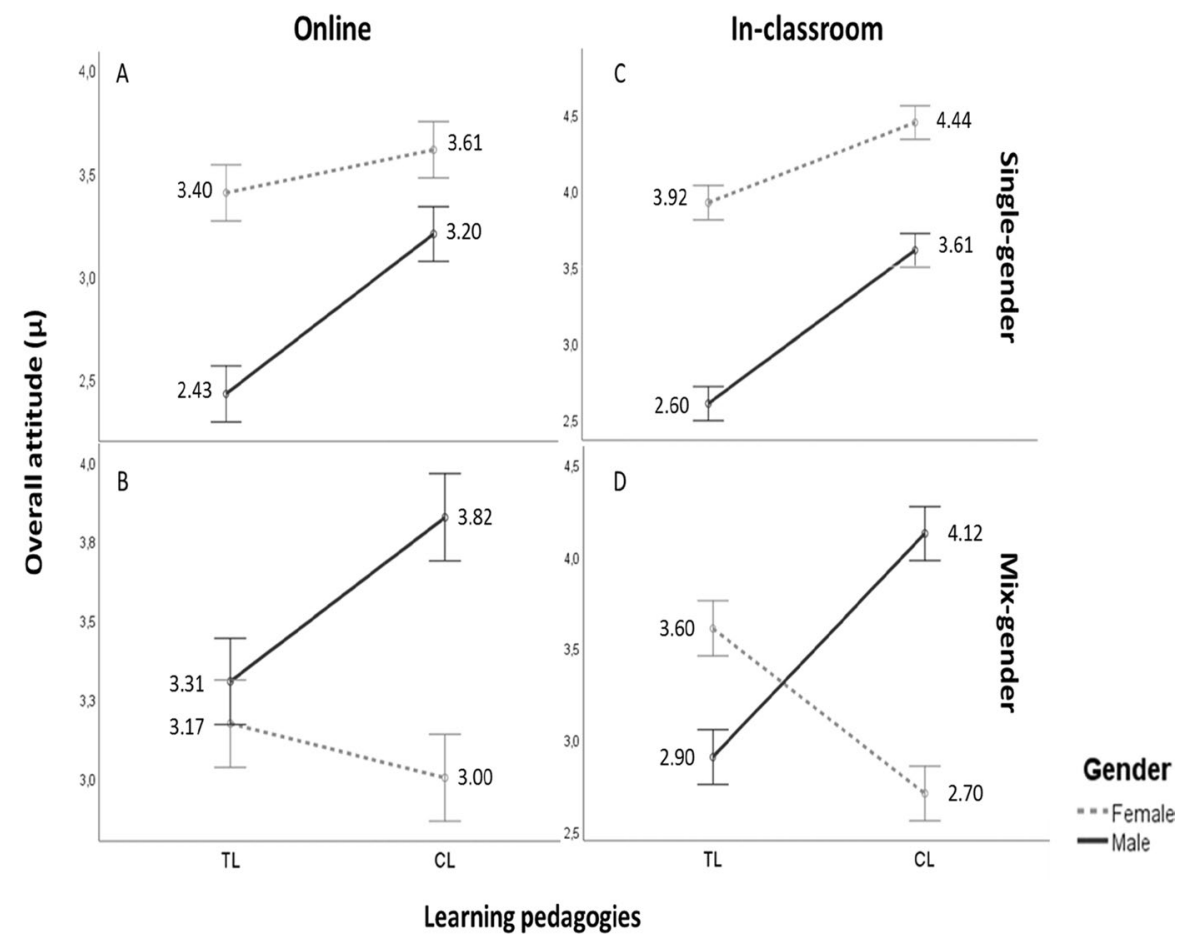

Fig. 6 Interaction effect between gender (female and male) x learning pedagogies (collaborative and traditional learning) for students' achievement in the different settings of the study: A) E-learning singlegender. B) E-learning mix-gender. C) In-classroom single-gender. D) In-classroom mix-gender. Means and standard deviations were represented in each graph 
pedagogy with e-learning and mix-gender as fixed levels, also affected significantly the variable of overall attitude $\left(\mathrm{F}(1,348)=24.43, \mathrm{p}<0.0001, \mathrm{R}^{2}=0.18\right)$ (Fig. 6B), and the categories of attention $\left(\mathrm{F}(1,347)=84.59, \mathrm{p}<0.000, \mathrm{R}^{2}=0.21\right)$, relevance $\left(\mathrm{F}(1,345)=22.56, \mathrm{p}<0.000, \mathrm{R}^{2}=0.16\right)$, confidence $(\mathrm{F}(1,348)=37.54, \mathrm{p}<0.000$, $\left.\mathrm{R}^{2}=0.20\right)$, and satisfaction $\left(\mathrm{F}(1,345)=19.50, \mathrm{p}<0.000, \mathrm{R}^{2}=0.24\right)$.

Achievement in e-learning biology Results supported hypothesis one (H1: F $>\mathrm{M}$ achievement in EL-SG-CL); female students outperformed $(\mu=81.48, \mathrm{SD}=6.16)$ male students $(\mu=78.14, \mathrm{SD}=5.42)$ in the e-learning single-gender collaborative setting $\left(\mathrm{F}(1,177)=14.83, \mathrm{p}<0.000, \mathrm{R}^{2}=33.56\right)$ with a large effect between means (Cohen's $d=0.77$ ) (Table 2, Fig. 7A). Hypothesis two (H2: F $>\mathrm{M}$ achievement in EL-SG-TL) was also supported; female students outperformed $(\mu=75.63, \mathrm{SD}=6.92)$ male students $(\mu=60.91, \mathrm{SD}=6.89)$ within the e-learning single-gender traditional setting $\left(\mathrm{F}(1,174)=200.19, \mathrm{p}<0,000, \mathrm{R}^{2}=47.64\right)$, with a large effect (Cohen's $d=2.13$ ) (Table 2, Fig. 7A). Hypothesis three (H3: M>F achievement in EL-MG$\mathrm{CL}$ ), was not fully supported since female and male students scored similar overall achievement in the e-learning mix-gender collaborative setting, with no significant

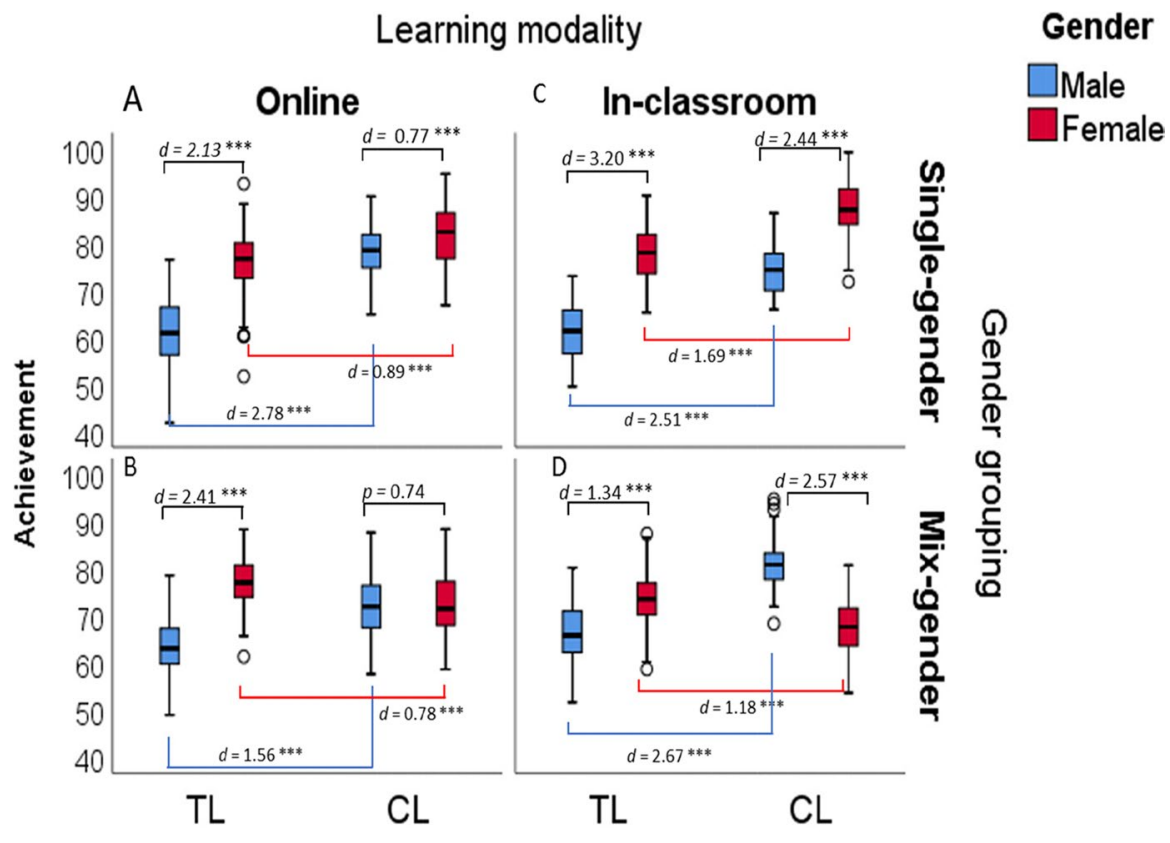

Learning pedagogies

Fig. 7 Achievement comparisons between female and male students in the different settings of the study: A) E-learning single-gender. B) E-learning mix-gender. C) In-classroom single-gender. D) Inclassroom mix-gender. Standard deviation and Cohens $d$ coefficient were represented in each graph $(* * *=\mathrm{p}<0.001)$. The $p$-value was presented to indicate non-significance between groups. References: CL: collaborative learning; TL: traditional learning 
differences between female $(\mu=72.56, \mathrm{SD}=5.85)$ and male $(\mu=72.27, \mathrm{SD}=5.70)$ students $\left(\mathrm{F}(1,174)=0.11, \mathrm{p}=0.74, \mathrm{R}^{2}=33.38\right)$ (Table 2, Fig. 7B). This result went contrary to what we observed for overall attitude in this setting. Similarly, hypothesis four (H4: $\mathrm{F}=\mathrm{M}$ attitude in EL-MG-TL) was not fully supported because in the e-learning mix-gender traditional setting, female students outperformed $(\mu=77.06$, $\mathrm{SD}=5.60)$ male students $(\mu=63.32, \mathrm{SD}=5.78) \quad(\mathrm{F}(1,174)=256.42, \mathrm{p}<0.000$, $\mathrm{R}^{2}=32.38$ ) (Table 2, Fig. 7B), with a large effect between means (Cohen's $d=2.41$ ).

When we evaluated if there were significant differences among same-gender students' overall achievement, we observed that female students within the e-learning single-gender collaborative setting $(\mu=81.48, \mathrm{SD}=6.16)$ scored significantly higher $(\mathrm{p}<0.000)$ compared to those females in the traditional setting $(\mu=75.63$, $\mathrm{SD}=6.92$ ), with a large effect between means (Cohen's $d=0.89)$ (Fig. 7A). Similarly, male students within the e-learning single-gender collaborative setting $(\mu=78.14, \mathrm{SD}=5.42)$ scored significantly higher $(\mathrm{p}<0.000)$ than those males within the traditional setting $(\mu=60.91, \mathrm{SD}=6.89)$, with a large effect between means (Cohen's $d=2.78$ ) (Fig. 7A). On the contrary, in the e-learning mix-gender collaborative setting, female students $(\mu=72.56, \mathrm{SD}=5.85)$ scored significantly lower $(\mathrm{p}<0.000)$ compared to those females in the traditional setting $(\mu=77.06$, $\mathrm{SD}=5.60$ ), with a large effect between means (Cohen's $d=0.78)$ (Fig. 7B). Whereas male students within the collaborative setting $(\mu=72.27, \mathrm{SD}=5.70)$ scored significantly higher $(\mathrm{p}<0.000)$ than those within the traditional setting $(\mu=63.32$, $\mathrm{SD}=5.78$ ), with a large effect between means (Cohen's $d=1.56)($ Fig. 7B).

\section{Interaction effects in e-learning}

The interaction between gender $\mathrm{x}$ learning pedagogy for e-learning and singlegender as fixed levels significantly affected the variable of overall achievement $(\mathrm{F}(1$, $351)=70.94, \mathrm{p}<0.000, \mathrm{R}^{2}=0.605$ ) (Fig. 8A). In addition, the interaction between gender $\mathrm{x}$ learning pedagogy for e-learning and mix-gender as fixed levels also significantly affected the variable of overall achievement $(\mathrm{F}(1,348)=120.96, \mathrm{p}<0.000$, $\mathrm{R}^{2}=0.43$ ) (Fig. 8B).

Correlation between overall attitudes and achievement scores online There was a positive correlation between female and male students' overall attitudes and achievement in all of the e-learning settings, both single-gender, and mix-gender (Fig. 9 A-D). As shown in Table 1, within the EL-SG settings, the correlation coefficient ranged between 0.70 and 0.84 . The lowest value corresponded to male students within the EL-SG-CL setting, while the highest value was for female students within the EL-SG-TL setting. Regarding EL-MG settings, the correlation coefficient ranged between 0.73 and 0.83 . The lowest value corresponded to male students within the EL-MG-TL setting, while the highest value was for female students within the EL-MG-CL setting. 


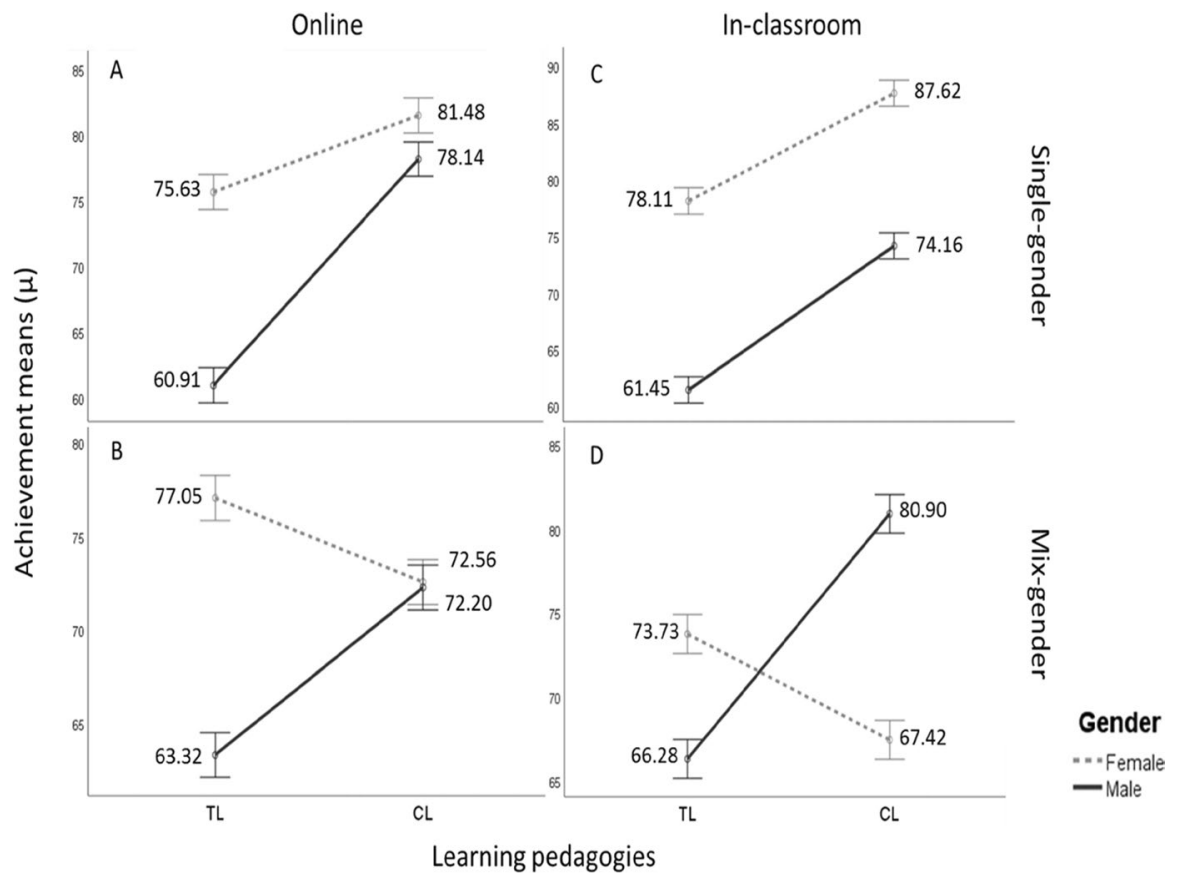

Fig. 8 Interaction effect between gender (female and male) x learning pedagogies (collaborative and traditional learning) for students' achievement in the different settings of the study: A) e-learning singlegender. B) e-learning mix-gender. C) In-classroom single-gender. D) In-classroom mix-gender. Means and standard deviations were represented in each graph. References: CL: collaborative learning; TL: traditional learning

Pre-test and post-test performance in e-learning The pre-test variable was not significantly affected by the interaction between the factors gender (F, M) x learning pedagogy (CL, TL), neither with e-learning and single-gender as fixed levels $\left(\mathrm{F}(1,351)=2.32, \mathrm{p}=0.128, \mathrm{R}^{2}=0.042\right)$ nor with e-learning and mix-gender as fixed levels $\left(\mathrm{F}(1,348)=1.54, \mathrm{p}=0.216, \mathrm{R}^{2}=0.05\right)$. In Table 2 , we observe that female students achieved higher pre-test scores than male students in the e-learning single-gender collaborative setting, whereas, in the EL-SG traditional setting, there were no significant differences between students. For EL-SG-CL: F(1,177) =12.95, $\mathrm{p}<0.000, \mathrm{R}^{2}=124.89$, and for EL-SG-TL: $\mathrm{F}(1,174)=2.09, \mathrm{p}=0.150, \mathrm{R}^{2}=122.50$. Similarly, in the e-learning mix-gender collaborative setting, female students achieved higher pre-test scores than male students, whereas no significant differences were observed in the EL-MG traditional setting. For EL-MG-CL: $(\mathrm{F}(1,174)=13.45$, $\mathrm{p}<0.000, \mathrm{R} 2=136.09$, and for EL-SG-TL: $\mathrm{F}(1,174)=2.73, \mathrm{p}=0.101, \mathrm{R} 2=165.67$.

The post-test variable was significantly affected by the interaction between the factors gender (F, M) x learning pedagogy (CL, TL) both with e-learning and singlegender as fixed levels $\left(\mathrm{F}(1,351)=19.63, \mathrm{p}<0.000, \mathrm{R}^{2}=0.17\right)$, and with e-learning and mix-gender as fixed levels $\left(\mathrm{F}(1,348)=123.86, \mathrm{p}<0.000, \mathrm{R}^{2}=0.30\right)$. In Table 2 , we observe those female students in the e-learning single-gender collaborative setting 


\section{Learning modality}

Online

\section{Learning pedagogies}

In-classroom

Learning pedagogies
Gender

Male

OFemale

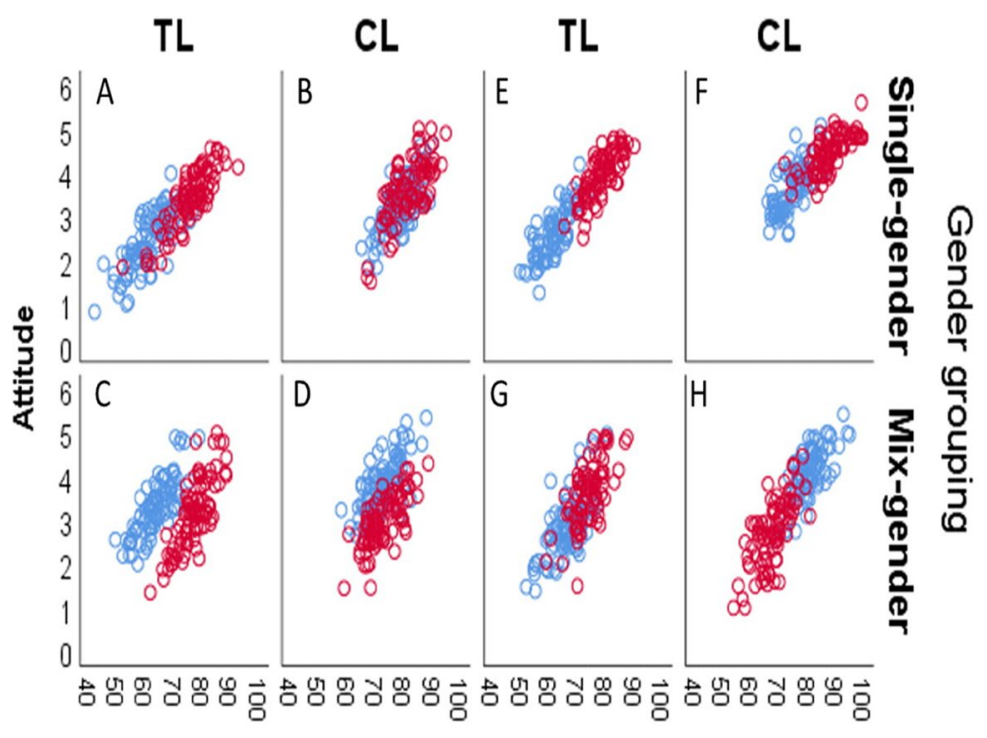

Achievement

Fig. 9 Correlation between attitude and achievement variables in the different settings of the study, represented by scatterplots for A) E-learning single-gender. B) E-learning mix-gender. C) In-classroom single-gender. D) In-classroom mix-gender. References: CL: collaborative learning; TL: traditional learning

achieved higher post-test scores than male students, whereas, in the EL-SG traditional setting, male students scored slightly higher than female students. Opposite results were observed in the e-learning mix-gender settings because, in the EL-MG collaborative setting, male students achieved higher post-test scores than female students, whereas, in the EL-MG traditional setting, female students scored higher than male students. For EL-SG-CL: $\mathrm{F}(1,177)=15.57, \mathrm{p}<0.000, \mathrm{R}^{2}=35.36$ ); EL-SGTL: $\mathrm{F}(1,174)=5.96, \mathrm{p}=0.016, \mathrm{R}^{2}=46.76$; EL-MG-CL: $\mathrm{F}(1,174)=19.84, \mathrm{p}<0.000$, $\mathrm{R}^{2}=29.09$; and EL-MG-TL: $\mathrm{F}(1,174)=126.60, \mathrm{p}<0.000, \mathrm{R}^{2}=29.67$.

\subsection{In-classroom learning modality}

This section was organized into sub-categories, according to hypotheses 5 to 8 . We proceed similarly to Sect. 5.1. First, we presented the analyses of each hypothesis, conducted through one-way ANOVA tests, to compare female and male students' overall attitude — and its four categories (attention, relevance, confidence, 
satisfaction)—, achievement, pre-test and post-test within each in-classroom learning setting. Then, we compared the overall attitudes and achievement within same-gender students' through T-tests. Finally, we evaluated the significance of the interaction between gender (F / M) x learning pedagogy (CL / TL) with e-learning (EL) and single-gender (SG) or mix-gender (MG) as the fixed levels of each factor through two-way ANOVA tests.

In Table 3, we arranged the data according to hypotheses 5 to 8 to examine female and male students' overall attitude and the four categories of the CIS; correlation scores between overall attitude and achievement were also provided. Table 4 arranged the data for female and male students' pre-test, post-test, and achievement; correlation scores between post-test and achievement were also provided.

\subsubsection{Hypotheses 5 to 8: In-classroom single-gender and mix-gender grouping within collaborative and traditional pedagogies}

Attitudes towards in-classroom biology Results supported hypothesis five (H5: $\mathrm{F}>\mathrm{M}$ attitude in IC-SG-CL); female students demonstrated significantly more positive attitudes towards biology $(\mu=4.44, \mathrm{SD}=0.42)$ than male students $(\mu=3.61$, $\mathrm{SD}=0.53)$ in in-classroom single-gender collaborative groups $(\mathrm{F}(1,166)=128.51$, $\mathrm{p}<0.000$, R2 =29.40) (Table 3, Fig. 4C), with a large effect between means (Cohen's $d=1.74$ ). Hypothesis six was also supported (H6: F $>\mathrm{M}$ attitude in IC-SG-TL); female students demonstrated significantly more positive attitudes $(\mu=3.92, \mathrm{SD}=0.53)$ than male students $(\mu=2.60, \mathrm{SD}=0.56)$ within the traditional setting $(\mathrm{F}(1,161)=237.078, \mathrm{p}<0.000$, R2 =70.62) (Table 3, Fig. 4C), with a large effect between means (Cohen's $d=2.42$ ). Hypothesis seven was supported as well (H7: $\mathrm{M}>\mathrm{F}$ attitude in IC-MG-CL); male students demonstrated significantly more positive overall attitude towards biology $(\mu=4.12, \mathrm{SD}=0.57)$ than female students $(\mu=2.70, \mathrm{SD}=0.76)$ in in-classroom mix-gender collaborative groups $\left(\mathrm{F}(1,168)=187.86, \mathrm{p}<0.000, \mathrm{R}^{2}=85.66\right)$ (Table 3, Fig. 4D), with a large effect between means (Cohen's $d=2.11$ ). On the contrary, hypothesis eight (H8: $\mathrm{F}=\mathrm{M}$ attitude in IC-MG-TL) was not supported; female students demonstrated significantly more overall positive attitude $(\mu=3.60, \mathrm{SD}=0.70)$ than male students $(\mu=2.90, \mathrm{SD}=0.74)$ within the traditional setting $(\mathrm{F}(1,165)=40.10, \mathrm{p}<0.000$, $\mathrm{R}^{2}=20.64$ ) (Table 3, Fig. 4D), with a large effect between means (Cohen's $d=0.97$ ).

When we evaluated if there were significant differences among same-gender students' overall attitudes, we observed that female students within in-classroom single-gender collaborative groups $(\mu=4.44, \mathrm{SD}=0.42)$ scored significantly higher $(\mathrm{p}<0.000)$ compared to those female students within the traditional setting $(\mu=3.92$, $\mathrm{SD}=0.53$ ), with a large effect between means (Cohen's $d=1.09$ ). Similarly, male students within the IC-SG collaborative setting $(\mu=3.61, \mathrm{SD}=0.53)$ demonstrated significantly higher overall attitude $(\mathrm{p}<000)$ than those in the IC-SG traditional setting $(\mu=2.60, \mathrm{SD}=0.56)$, with a large effect between means (Cohen's $d=1.84)$. On the contrary, within the in-classroom mix-gender collaborative setting, female students $(\mu=2.70, \mathrm{SD}=0.76)$ scored significantly lower $(\mathrm{p}<0.000)$ compared to those female students within the IC-MG traditional setting $(\mu=3.60, \mathrm{SD}=0.70)$, with a large effect between means (Cohen's $d=1.23$ ). In contrast, male students within the 


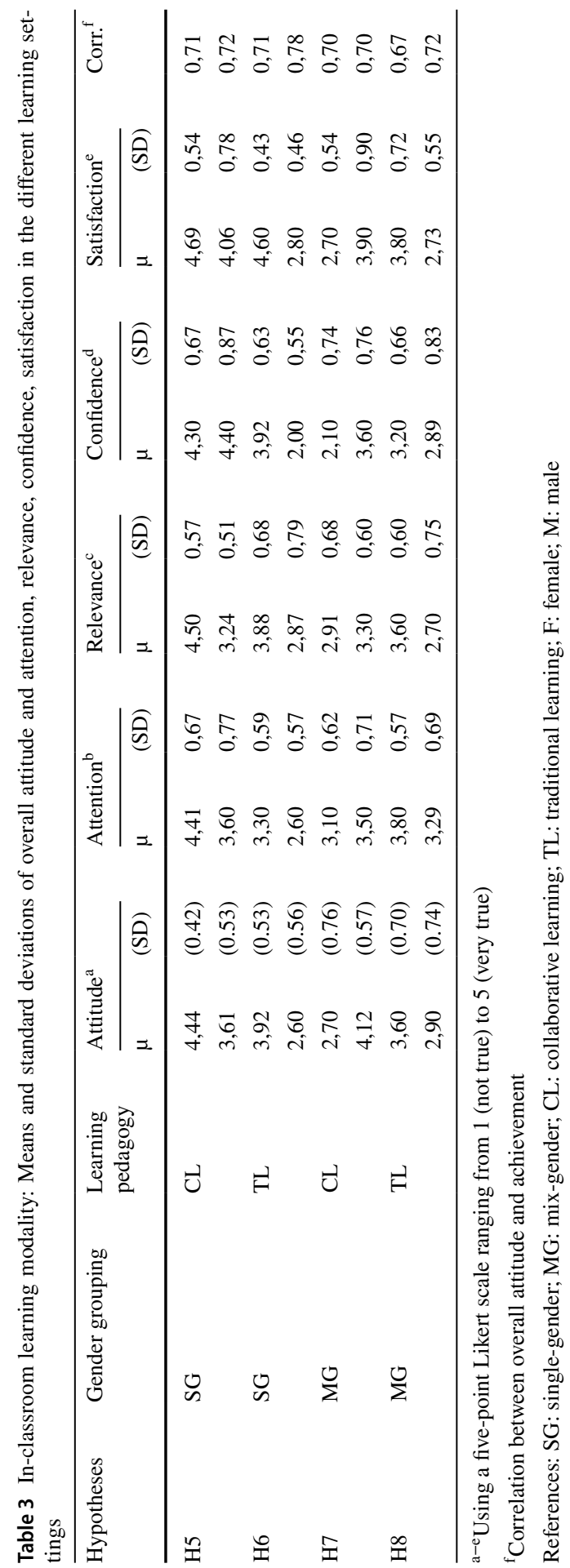




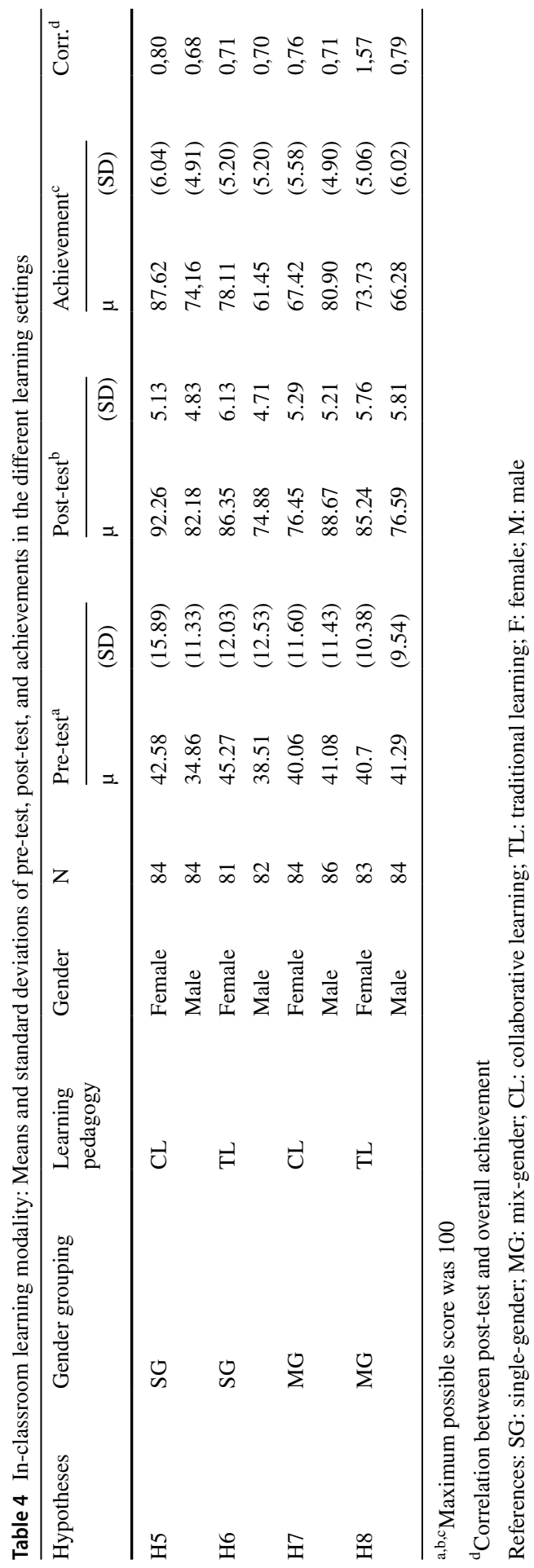


IC-MG collaborative setting $(\mu=4.12, \mathrm{SD}=0.57)$ demonstrated significantly higher overall attitude $(\mathrm{p}<000)$ than those in the IC-MG traditional setting $(\mu=2.90$, $\mathrm{SD}=0.74)$, with a large effect between means (Cohen's $d=1.85$ ).

\section{ARCS categories of attitude in-classroom}

After evaluating each sub-category of attitude, results showed that female students experienced significantly higher attention, relevance, and satisfaction than male students in-classroom single-gender collaborative and traditional settings, with the unique exception that there were no significant differences between students' confidence in both settings (Fig. 5E-H). In the collaborative settings, for attention $\mathrm{F}(1,166)=53.74, \mathrm{p}<0.000, \mathrm{R}^{2}=27.88$, for relevance $\mathrm{F}(1,166)=225.03$, $\mathrm{p}<0.000, \mathrm{R}^{2}=66.20$, and for satisfaction $\mathrm{F}(1,166)=36.13, \mathrm{p}<0.000, \mathrm{R}^{2}=16.16$. Whereas in the traditional settings, for attention $(\mathrm{F}(1,161)=57.77, \mathrm{p}<0.000$, $\left.\mathrm{R}^{2}=19.64\right)$, for relevance $\mathrm{F}(1,161)=77.66, \mathrm{p}<0.000, \mathrm{R}^{2}=41.88$, and for satisfaction $\mathrm{F}(1,161)=658.34, \mathrm{p}<0.000, \mathrm{R}^{2}=131.58$.

In contraposition, in the in-classroom mix-gender collaborative setting, male students experienced significantly higher attention, relevance, confidence and satisfaction than female students (Fig. 5E-H). Whereas opposite results were observed for the IC-MG traditional setting, in which female students experienced significantly higher attention, relevance, confidence and satisfaction than male students. In the collaborative settings, for attention $\mathrm{F}(1,167)=15.45, \mathrm{p}<0.000, \mathrm{R}^{2}=6.95$, for relevance $F(1,168)=15.38, p<0.000, R^{2}=6.33$, for confidence $F(1,167)=168.74$, $\mathrm{p}<0.000, \mathrm{R}^{2}=94.60$, and for satisfaction $\mathrm{F}(1,167)=108.84, \mathrm{p}<0.000, \mathrm{R}^{2}=60.30$. Whereas in the traditional settings, for attention $(\mathrm{F}(1,165)=27.18, \mathrm{p}<0.000$, $\mathrm{R}^{2}=10.95$ ), for relevance $\mathrm{F}(1,165)=73.21, \mathrm{p}<0.000, \mathrm{R}^{2}=33.94$, for confidence $F(1,165)=7.46, p=0.007, R^{2}=4.17$, and for satisfaction $F(1,165)=118.99$, $\mathrm{p}<0.000, \mathrm{R}^{2}=48.35$.

\section{Interaction effects in-classroom}

The interaction between gender $\mathrm{x}$ learning pedagogy with in-classroom and single-gender as fixed levels significantly affected the variable of overall attitude $\left(\mathrm{F}(1,327)=18.12, \mathrm{p}<0.000, \mathrm{R}^{2}=0.63\right)$, and the categories of relevance $\left(\mathrm{F}(1,327)=2.91, \mathrm{p}=0.089, \mathrm{R}^{2}=0.49\right)$, confidence $(\mathrm{F}(1,327)=177.26, \mathrm{p}<0.000$, $\left.\mathrm{R}^{2}=0.67\right)$, and satisfaction $\left(\mathrm{F}(1,327)=87.956, \mathrm{p}<0.000, \mathrm{R}^{2}=0.64\right)$. It did not affect attention $\left(F(1,327)=0.70, p=0.40, R^{2}=0.50\right)$. In Fig. $6 C$ we represented this interaction and observed that female and male students demonstrated a higher overall attitude in CL than TL within in-classroom single-gender settings. The interaction between gender $x$ learning pedagogy with in-classroom and mix-gender as fixed factors also affected significantly the variable of overall attitude $(\mathrm{F}(1,333)=195.66$, $\left.\mathrm{p}<0.000, \mathrm{R}^{2}=0.40\right)$, and the categories of attention $(\mathrm{F}(1,332)=41.46, \mathrm{p}<0.000$, $\left.\mathrm{R}^{2}=0.14\right)$, relevance $\quad\left(\mathrm{F}(1,333)=79.84, \quad \mathrm{p}<0.000, \quad \mathrm{R}^{2}=0.22\right), \quad$ confidence 
$\left(\mathrm{F}(1,327)=177.26, \quad \mathrm{p}<0.000, \quad \mathrm{R}^{2}=0.35\right), \quad$ and satisfaction $(\mathrm{F}(1,332)=225.30$, $\left.\mathrm{p}<0.000, \mathrm{R}^{2}=0.41\right)$. In Fig. $6 \mathrm{D}$ we represented this interaction and observed that while female students demonstrated higher overall attitude in TL, male students experienced higher attitude in CL within in-classroom mix-gender settings.

Achievement in in-classroom biology

Results supported hypothesis five (H5: F $>$ M achievement in IC-SG-CL); since female students outperformed $(\mu=87.62, \mathrm{SD}=6.04)$ male students $(\mu=74.16$, $\mathrm{SD}=4.91)$ in in-classroom single-gender collaborative groups $(\mathrm{F}(1,166)=251.28$, $\mathrm{p}<0.000, \mathrm{R} 2=30.26$ ) (Table 4, Fig. 15) with a large effect between means (Cohen's $d=2.44$ ). Hypothesis six was also supported; female students outperformed $(\mu=78.11, \mathrm{SD}=5.20)$ male students $(\mu=61.45, \mathrm{SD}=5.20)$ within the traditional setting $(\mathrm{F}(1,161)=418.11, \mathrm{p}<0.000, \mathrm{R} 2=27.02)$ (Table 4, Fig. 15), with a large effect (Cohen's $d=3.20)$. Results supported hypothesis seven as well $(\mathrm{H} 7: \mathrm{M}>\mathrm{F}$ achievement in IC-MG-CL); male students outperformed $(\mu=80.90, \mathrm{SD}=4.90)$ female students $(\mu=67.42, \mathrm{SD}=5.58)$ in in-classroom mix-gender collaborative groups $\left(F(1,168)=280,61, p<0.000, R^{2}=27,51\right)$ (Table 4, Fig. $7 C$ ), with a large effect between means (Cohen's $d=2.57$ ). But contrary to hypothesis eight (H8: $\mathrm{F}=\mathrm{M}$ attitude in IC-MG-TL), and in line with overall attitude results, females outperformed $(\mu=73.73, \mathrm{SD}=5.06)$ male students $(\mu=66.28, \mathrm{SD}=6.02)$ in the traditional setting $\left(F(1,165)=74.95, p<0.000, R^{2}=30.90\right)$ (Table 4, Fig. 7D), with a large effect between means (Cohen's $d=1.34$ ).

When we evaluated if there were significant differences among same-gender students' achievement, we observed that female students within in-classroom single-gender collaborative groups $(\mu=87.62, \mathrm{SD}=6.04)$ scored significantly higher $(\mathrm{p}<0.000)$ compared to those in the IC-SG traditional setting $(\mu=78.11, \mathrm{SD}=5.20)$, with a large effect between means (Cohen's $d=1.69$ ). Similarly, male students within the IC-SG collaborative setting $(74.16, \mathrm{SD}=4.91)$ scored significantly higher $(\mathrm{p}<0.000)$ than those males within the IC-SG traditional setting $(\mu=61.45$, $\mathrm{SD}=5.20$ ), with a large effect between means (Cohen's $d=2.51$ ). In contraposition, in the in-classroom mix-gender collaborative setting, female students $(\mu=67.42$, $\mathrm{SD}=5.58)$ scored significantly lower $(\mathrm{p}<0.000)$ compared to those females in the traditional setting $(\mu=73.73, \mathrm{SD}=5.06)$, with a large effect between means (Cohen's $d=1.18$ ). In contrast, male students within the IC-MG collaborative setting $(\mu=80.90, \mathrm{SD}=4.90)$ scored significantly higher $(\mathrm{p}<0.000)$ than those within the IC-MG traditional setting $(\mu=66.28, \mathrm{SD}=6.02)$, with a large effect between means (Cohen's $d=2.67$ ).

\section{Interaction effects in-classroom}

The interaction between gender $\mathrm{x}$ learning pedagogy with in-classroom and single-gender as fixed factors significantly affected the variable of overall achievement 
$(\mathrm{F}(1,327)=7.37, \mathrm{p}=0.007, \mathrm{R} 2=0.76)(\mathrm{Fig} .8 \mathrm{C})$. The interaction between gender $\mathrm{x}$ learning pedagogy with in-classroom and mix-gender as fixed factors also significantly affected the variable of overall achievement $(F(1,333)=315.94, p<0.000$, $\mathrm{R}^{2}=0.54$ ) (Fig. 8D).

Correlation between attitudes and overall achievement scores There was a positive correlation between female and male students' overall attitudes and achievement in all e-learning settings, both single-gender and mix-gender (Fig. 9A-D). As shown in Table 1, within the EL-SG settings, the correlation coefficient ranged between 0.70 and 0.84. The lowest value corresponded to male students within the EL-SG-CL setting, while the highest value was for female students within the EL-SG-TL setting. Regarding IC-MG settings, the correlation coefficient ranged between 0.71 and 0.79 . Again, the lowest correlation corresponded to male students within the IC-MG-CL setting, while the highest to male students within the IC-MG-TL setting.

Pre-test and post-test performance in-classroom The pre-test variable was not significantly affected by the interaction between the factors gender (F, M) x learning pedagogy (CL, TL), neither with in-classroom and single-gender as fixed levels $\left(\mathrm{F}(1,327)=0.11, \mathrm{p}=0.74, \mathrm{R}^{2}=0.08\right)$, nor with in-classroom and mix-gender as fixed levels $\left(F(1,333)=0.03, p=0.86, R^{2}=0.002\right)$. In Table 4 female students achieved higher pre-test scores than male students in both the in-classroom single-gender collaborative and traditional settings. Whereas in the in-classroom mix-gender collaborative and traditional settings, female and male students achieved similar pre-test scores, with no significant differences. For IC-SG-CL: $F(1,166)=13.15, \mathrm{p}<0.000$, $\mathrm{R}^{2}=190.44 ; \quad$ IC-SG-TL: $\quad \mathrm{F}(1,174)=2.73, \quad \mathrm{p}=0.101, \quad \mathrm{R}^{2}=165.67 ; \quad$ IC-MG-CL: $\mathrm{F}(1,166)=13.15, \mathrm{p}<0.000, \mathrm{R}^{2}=190.44$; and IC-MG-TL: $\mathrm{F}(1,174)=2.73, \mathrm{p}=0.10$, $\mathrm{R}^{2}=165.67$.

The post-test variable was not significantly affected by the interaction between the factors gender $(\mathrm{F}, \mathrm{M}) \mathrm{x}$ learning pedagogy (CL, TL) in-classroom and singlegender as fixed levels $\left(\mathrm{F}(1,327)=1.48, \mathrm{p}=0.22, \mathrm{R}^{2}=0.60\right)$. In Table 4 , we observe that female students achieved higher post-test scores than male students in the inclassroom single-gender collaborative and traditional settings. In contrast, the interaction between the factors gender $(\mathrm{F}, \mathrm{M}) \mathrm{x}$ learning pedagogy (CL, TL) in-classroom and MIX-gender as fixed levels was significantly affected by the interaction $(\mathrm{F}(1,333)=299.61, \mathrm{p}<0.000, \mathrm{R} 2=0.49)$. In Table 4 , we observe that female students achieved higher post-test scores than male students in the in-classroom mixgender collaborative and traditional settings. For IC-SG-CL: $F(1,166)=171.69$, $\mathrm{p}<0.000, \quad \mathrm{R}^{2}=24.81 ; \mathrm{IC}-\mathrm{SG}-\mathrm{TL}: \mathrm{F}(1,161)=179.69, \mathrm{p}<0.000, \mathrm{R}^{2}=29.82 ; \mathrm{IC}-\mathrm{MG}-$ CL: $\mathrm{F}(1,166)=171.69, \mathrm{p}<0.000, \mathrm{R} 2=24.81$; and IC-MG-TL: $\mathrm{F}(1,168)=228.76$, $\mathrm{p}<0.000, \mathrm{R} 2=27.55$. 


\subsection{Intervention effect between pre-test and post-test scores: e-learning vs. in-classroom}

For both female and male students, the post-test scores were higher than the pre-tests for all the interventions assessed. These results indicated that students improved their acquired knowledge before and after taking the biology course. To reveal the extent of this improvement, we further analyzed the increase in the pre-post change (or intervention effect) between pre-test and post-test scores in the experimental setting (online) compared to the control setting (in-classroom) among the different interventions (Table 5). The analyses showed that female students greatly improved achievement (68.2\%) in the e-learning single-gender collaborative setting compared to the control IC-SG-CL setting, whereas males showed a slight improvement between such settings (3.7\%). When we analyzed the e-learning single-gender traditional setting, we observed female students indeed improved achievement (14.6\%), while male students barely improved (1.1\%). A contrary tendency was observed for female students within the e-learning mix-gender collaborative setting, where they barely improved achievement (2.7\%), whereas male students strongly did it $(102.1 \%)$. For the e-learning mix-gender traditional setting, female students showed a slight increase in the pre-post change (3.4\%), similar to male students $(3.1 \%)$ (Table 5) again.

The Pre-Post change or intervention effect was calculated between the e-learning and in-classroom settings.

\section{Discussion}

This research aimed to investigate and evaluate how undergraduate female and male students' attitudes and achievement in biology were influenced within e-learning and in-classroom settings, designed and implemented using collaborative and traditional learning pedagogies in single-gender and mix-gender groupings. The GCC countries face the excellent opportunity to take advantage of the educational revolution that the internet, new technologies, and the collaborative pedagogy have encouraged, particularly in STEM disciplines (Almasri, 2022; Austin, 2017; Vision and Change in Undergraduate Biology Education 2010), to support new pedagogical practices and adapt them to their particular cultures (Kim, 2008; Örnek, 2015). It is drawn that what works in one country does not necessarily work in another because each culture has its socio-cultural variables. The findings will shed light on further designing, evaluating,

Table 5 Pre-Post change between e-learning and in-classroom settings

\begin{tabular}{|c|c|c|c|c|c|c|c|}
\hline \multicolumn{4}{|c|}{ Single-gender } & \multicolumn{4}{|c|}{ Mix-gender } \\
\hline \multicolumn{2}{|c|}{$\begin{array}{l}\text { Collaborative } \\
\text { Learning }\end{array}$} & \multicolumn{2}{|c|}{$\begin{array}{l}\text { Traditional } \\
\text { Learning }\end{array}$} & \multicolumn{2}{|c|}{$\begin{array}{l}\text { Collaborative } \\
\text { Learning }\end{array}$} & \multicolumn{2}{|c|}{$\begin{array}{l}\text { Traditional } \\
\text { Learning }\end{array}$} \\
\hline Female & Male & Female & Male & Female & Male & Female & Male \\
\hline 68,24 & 3,70 & 14,66 & 1,08 & 2,67 & 102,10 & 3,37 & 3,12 \\
\hline
\end{tabular}


and implementing personalized learning settings for students within the GCC countries. Hereafter, we presented an overview of the influence of sociocultural context on the present findings. After that, since this study concerns the e-learning and in-classroom modalities, we evaluated the first four hypotheses that refer to the experimental e-learning settings in terms of students' attitudes and achievement, and the effect learning pedagogies, gender, and gender grouping had on both variables, comparing to the other four hypotheses related to the control in-classroom settings.

\subsection{Influence of the socio-cultural context and social identities on learning in the GCC countries}

The Gulf countries are characterized by a religious ideology, rapid economic changes, and developing social infrastructures (Mansour \& Al-Shamrani, 2015b). They share similar socio-cultural contexts with gender-segregated educational systems, which leads to rooted differences between female and male students (Alsuwailan, 2006; Dakhli et al., 2010; Dakhli \& El-Zohairy, 2013; Lightfoot, 2014; Mansour \& Al-Shamrani, 2015b; The World Bank, 2019). With the vision to improve education at all levels, the GCC countries have imported curricula, educational systems, technologies, methods, and standards from Western countries without considering the differences between their own needs and cultures (Mansour \& Al-Shamrani, 2015b). In particular, they have based higher education on the American model (AlKhaldi 2007b; Singera et al., 2014). This lack of consideration of the socio-cultural contexts hinders general education development and science education in GCC countries (Mansour, 2013; Mansour \& Al-Shamrani, 2015b).

As stated by Vygotsky, "learning cannot be separated from its socio-cultural context" (Vygotsky, 1978). Therefore, students carry their attitudes towards biology into the classroom-based upon their sociocultural background influence (Örnek, 2015). Thus, GCC countries should take a socio-cultural perspective on biology education to adapt the borrowed educational models; in other words, they should address biology education bonded to the socio-cultural variables of the countries such as religion, language, economic status, lifestyle, gender, ethnicity, inequality, politics, values, habits, memories and history (Mansour \& Al-Shamrani, 2015b; Wickman \& Östman, 2002).

Most of the elementary and secondary schools as well as Gulf universities, continue to practice some form of gender segregation either through separate males' and females' schools, separate courses, physically separate campuses, or classroom seating arrangements (Karafyllis, 2015a; Mahboob \& Elyas, 2017; Mansour \& AlShamrani, 2015b). The fact remains that many Gulf families and females are more comfortable in a gender-separated environment (McClusky, 2017). This is reflected in the educational system as well (Al-Fadhli, 2008; Al-Fadhli \& Khalfan, 2009). It was posited that the e-learning modality might encourage and benefit students who prefer to limit their interactions with peers and instructors from the opposite gender (Lansari et al., 2007; Weber, 2010) to overcome their traditional reticence in mixed-gender groups. Particularly maybe valid for female students who are most affected by stricter rules of interaction and communication than male students 
(Al-Fadhli, 2008). Many studies suggested females in same-gender groups outperformed females in mixed-gender groups (Almasri Firas et al., 2021; Barbieri \& Light, 1992; Ding \& Harskamp, 2006; Light et al., 2000; Siann \& Macleod, 1986).

\subsection{Attitude and achievement towards biology based on students' gender and learning pedagogies within e-learning single-gender settings}

Several external factors can affect students' attitudes towards biology and pursuing biology-related careers positively or negatively, including the learning environment, quality of instruction, peer influence, parental influence, gender, culture, and ethnicity (Collins \& Simon, 2006; Jinks \& Morgan, 1999; Mansour, 2013; Mansour \& Al-Shamrani, 2015b; Örnek, 2015). In this study, one of the focuses was put on the interplay of gender in different learning settings implemented to establish the most conducive context-based pedagogies for female and male undergraduate biology students.

Our findings showed that female students experienced more positive overall attitudes and scored higher in attention, relevance, confidence, and satisfaction than male students in the e-learning modality, in collaborative and traditional single-gender settings, with a medium and high effect respectively. According to the sociocultural context of the study, we expected female students to feel more comfortable and satisfied with learning within single-gender settings. Our results confirmed that female students paid more attention and felt more confident than their male peers in these kinds of learning arrangements. Other researchers found similar results who posed that female students experienced greater satisfaction in a novel computersupported environment (González-Gómez et al., 2012) and were more inclined to work with each other in a community atmosphere (Agnew et al., 2008). Moreover, female students' demonstrated similar attitudes either learning in collaborative and traditional environments when they were single-gender grouped in the e-learning modality. Other researchers similarly concluded that females preferred single-gender groupings regardless of the learning pedagogy implemented in e-learning environments (Zhan et al., 2015a). Nevertheless, male students experienced more positive overall attitudes when learning in group-based collaborative than in student-centred traditional e-learning environments, these findings aligned with earlier research where male students enjoyed a premium in the traditional classroom setting (Gratton-Lavoie \& Stanley, 2009).

Female students scored higher achievements than male students in the e-learning modality, in both collaborative and traditional single-gender settings, with a significant effect in both cases. Moreover, female and male students profited more from the collaborative e-learning setting than the traditional e-learning one. While females reached almost 5 points of difference in favour of the e-learning collaborative pedagogy, males also significantly outperformed in this setting with almost seventeen points of difference with respect to the traditional e-learning setting. These results supported the idea that collaborative learning environments implemented in an e-learning modality effectively enhance students' attitudes and achievement, similarly as posed previously (Zhan et al., 2011). Ample evidence 
supports a positive relationship between attitudes towards a subject and the achieved scores (Ahmad \& Asghar, 2011; Nasr \& Soltani, 2011). Through our results, we could also support this widely recognized statement. We observed a positive correlation between overall attitude and achievement for female and male students within the four e-learning settings, with the highest correlation coefficient for females in the e-learning mix-gender collaborative setting and the lowest for females in the e-learning single-gender collaborative setting.

\subsection{Attitude and achievement towards biology based on students' gender and learning pedagogies within e-learning mix-gender settings}

Gender is an important factor in collaborative learning (Hewapathirana \& Almasri, 2022; Harskamp et al., 2008). It seems to have a more significant effect in conservative societies with gender-segregated educational systems, where females and males do generally not intermix socially outside of the family unit (Mahboob \& Elyas, 2017). We found that in the e-learning mix-gender collaborative setting, male students experienced more positive overall attitudes and scored higher in attention, confidence, and satisfaction than female students, with a large effect. Male students demonstrated the highest overall attitude among the e-learning settings and exceeded their female peers by almost one point in this setting. In prior research, similar findings were found in which authors concluded that male students preferred mixed-gender grouping where they achieved the best attitudes towards the course (Zhan et al., 2015a).

Despite male students experiencing more positive attitudes than their female peers in the e-learning mix-gender collaborative setting, female students could achieve similar scores than males. Thus, hypothesis three was not fully supported. Our findings demonstrated that e-learning could ease the negative impact of mixed-gender grouping on female students, as other authors suggested (Al-Fadhli, 2008; Lansari et al., 2007; Mahboob \& Elyas, 2017). In addition, similar results were achieved in a research carried out in Oman where the instructor stated that "online tools seemed to have encouraged my female Omani students to formulate and express their opinions and to communicate with their male counterparts at a level that would probably be unthinkable in a face-to-face educational situation" (Heble, 2007). One possible explanation is that female students experienced a more positive attitude towards e-learning - possibly managing better e-learning tools - than males, making the difference despite their lower attitudes towards the course. Yet, more research needs to be performed to study this issue and understand these results.

On the other hand, in e-learning mix-gender traditional settings, male students experienced similar attitudes as females did, which was expected according to hypothesis four. Females felt more comfortable learning individually within virtual workspaces in the e-learning mix-gender traditional setting because they experienced slightly higher overall attitudes than in the e-learning mix-gander collaborative setting and thus demonstrated similar attitudes than their male peers. Also, in this setting, females paid more attention but showed less relevance and satisfaction towards the course than male students. Again, the socio-cultural context affected differentially female and male students' attitudes towards biology, supporting previous studies that posed the necessity to 
implement context-based learning environments for each gender within conservative societies (Almasri Firas et al., 2021; Brownell et al., 2013; Cen et al., 2014; Colbeck et al., 2001).

Contrary to the fact that female and male students experienced similar attitudes, females outperformed males in the e-learning mix-gender traditional setting. Hence, hypothesis four was not fully supported. Within e-learning mix-gender settings, regardless of the learning pedagogy, we did not find a correlation between attitudes towards the biology course and the achieved scores. In this case, the positive effect of the e-learning modality seemed to have prevailed over the negative effect of mix-gender groupings. It was likely that e-learning encouraged female students to overcome their traditional reticence in mixed-gender groups allowing them to achieve higher outcomes in biology than their male peers. Our findings agreed with many authors who posed that the e-learning modality might ease the impact of gender differences between female and male students in such conservative and gender-segregated cultures (Al-Fadhli, 2008; Karafyllis, 2015b; Mahboob \& Elyas, 2017).

\subsection{Attitude and achievement towards biology based on students' gender and learning pedagogies within in-classroom single-gender settings}

Female students experienced more positive overall attitudes and scored higher in attention, relevance, and satisfaction than male students in the in-classroom single-gender collaborative and traditional settings, with a significant effect in each case. The wellreported benefits of collaborative learning environments over the traditional approach, especially for learning biology (Cen et al., 2016b; Freeman et al., 2014a; Iborra et al., 2009; Stump, Hilpert, et al., 2011; Takeda et al., 2017), were reflected in our results. Both female and male students demonstrated more positive attitudes towards the course when learning within groups rather than individually. Besides, females profited more than males, showing one point above the attitude scale in the collaborative and traditional learning settings. Our current findings agreed with a previous study that we carried out in a university in Kuwait, where major and nonmajor female students experienced significantly higher attitudes towards biology than male students in both collaborative and traditional pedagogies (Almasri et al., 2021).

There was a positive correlation between attitudes and achievement because female students outperformed their male peers in both the collaborative and traditional classroom in the single-gender settings, with a significant effect in each case. Hence, the results supported hypotheses five and six. Moreover, females performed ten points above male students in the in-classroom single-gender collaborative setting, while this difference was even more significant in the traditional setting where females outperformed males by almost twelve points.

\subsection{Attitude and achievement towards biology based on students' gender and learning pedagogies within in-classroom mix-gender settings}

Male students demonstrated more positive attitudes and scored higher in the four categories of attention, relevance, confidence, and satisfaction in the in-classroom 
mix-gender collaborative setting; thus, partially supporting hypothesis seven. In addition, male students experienced the highest attitudes scores in this setting, while females scored the lowest. In keeping with these findings, we discovered a positive relationship between female and male student success, as male students outperformed their female colleagues in a mixed-gender collaborative classroom setting, with a significant effect. Similarly, some researches showed that in physics education in mixed-gender groups, there was a gender difference in male students' achievement in the higher grades, while there was no significant gender difference in learning results at the middle-school level (Burkam et al., 1997; Osborne \& Dillon, 2008). Moreover, other studies indicated that female students profited less than male students from mixed-gender collaborative learning in physics (Ding \& Harskamp, 2006).

On the contrary, female students demonstrated more positive overall attitude and attention, relevance, confidence, and satisfaction in the in-classroom mixgender traditional setting, contrary to what was expected according to hypothesis eight. It was likely that traditional pedagogy eased females' reticence in mixedgender groups. One possible explanation was that despite sharing the classroom, female students were physically separated from their male peers without or with scarce face-to-face interaction; they stood on one side of the classroom and male students on the opposite one. This situation might have led them to feel more confident and satisfied in the learning environment, experiencing more attention, feeling the course more relevant, and thus demonstrating more positive overall attitudes reflected in high achievements in biology. Female students performed almost ten points above male students in the in-classroom mix-gender traditional setting. We supported such differences between females' achievement in collaborative vs. traditional settings due to the social identities determined by the conservative society.

\section{Academic implications of the study}

This study brings solid and novel quantitative insights and context-based evidence of the impact of gender-groupings and learning pedagogies in undergraduate female and male students' attitudes and achievement in a biology course. Specifically, it brings concrete data about the positive effect e-learning has to attenuate social identities and social-culture differences between female and male students in a conservative and gender-segregated culture such as in the GCC countries. This valuable information might be carefully studied and the possibility of its application evaluated by the educational institutions, educators, instructors within the GCC countries. For example, instructors could encourage pilot tests in their classes to evaluate the extent of the impact of e-learning in female students' performance and attitudes when learning within collaborative mixedgender groupings. And if results are encouraging, educational institutions should promote e-learning, especially among female students. 


\section{Limitations of the study}

We posed the importance of specifying the socio-cultural context in which studies, in general, are implemented to avoid biased and potentially inaccurate generalizations of results (Brownell et al., 2013). Thus, since we presented a study case within undergraduate biology students, what we found here is valid for Kuwait's educational system and might be extended to GCC countries in the Middle East but might not apply to other non-middle eastern developing countries. Moreover, the study was performed with biology undergraduate students, so more knowledge is needed to conclude whether these findings are applicable for other STEM disciplines or students in different educational levels. Finally, among many factors that influence the classroom experience, one that has been found to have a specific influence on students' achievement and participation is instructor gender (Eddy et al., 2014; Hoffmann F and P 2009). Furthermore, this factor might especially affect the classrooms within conservative societies such as the GCC, but we did not address this issue in the current research. Thus, it should be further investigated to bring insights into whether gender instructors might affect learning settings in a university in Kuwait.

\section{Conclusion}

The study brings quantitative insights and context-based evidence that supports the election of the most conducive pedagogical settings for female and male students within a conservative gender-segregated society such as the GCC countries. All students' attitudes and achievements were significantly affected according to the different learning settings. However, the conservative socio-cultural context where the study was carried out, and the rooted gender-segregated rules of the society, affected mainly female students' attitudes and achievement. While females demonstrated more positive attitudes and achievement in single-gender settings, male students experienced more positive attitudes and achieved higher scores in mixed-gender collaborative environments, either e-learning or in-classroom. Females only performed more positively when the collaborative learning environments were implemented in either e-learning or in-classroom single-gender groups, while males preferred collaborative learning environments regardless of gender-grouping and learning modalities. E-learning modality may encourage female students to overcome the socio-cultural barrier that leads them to feel reticence in mixed-gender groups. Finally, due to the political framework of the GCC countries and the strong cultural ties and common social, religious, and economic concerns, the context-based evidence of this study will be instrumental in regional knowledge development and sharing. Understanding the most suitable learning settings for female and male students will help decrease gender disparities, reduce the negative influences of social identities in different socio-cultural, and develop learning strategies to equalize opportunities for all students that result in a more positive attitude and higher achievement in biology education. 
Open Access This article is licensed under a Creative Commons Attribution 4.0 International License, which permits use, sharing, adaptation, distribution and reproduction in any medium or format, as long as you give appropriate credit to the original author(s) and the source, provide a link to the Creative Commons licence, and indicate if changes were made. The images or other third party material in this article are included in the article's Creative Commons licence, unless indicated otherwise in a credit line to the material. If material is not included in the article's Creative Commons licence and your intended use is not permitted by statutory regulation or exceeds the permitted use, you will need to obtain permission directly from the copyright holder. To view a copy of this licence, visit http://creativeco mmons.org/licenses/by/4.0/.

\section{References}

Abdeldayem MM, Al Dulaimi SHJJJAST. (2020). Trends ofglobal fintech education practices and the gcc perspective. 29:7150-7163.

Adams, J., \& Morgan, G. (2007). "Second Generation” E-Learning: Characteristics and Design Principles for Supporting Management Soft-Skills Development. International Journal on E-Learning, $6(2), 157-185$.

Adams JD, Avraamidou L, Bayram-Jacobs D, Boujaoude S, Bryan L, Christodoulou A, Couso D, Danielsson A, Dillon J, Erduran S et al. (2018) The role of science education in a changing world.

Adom D, Yeboah A, Ankrah AK. (2017). Constructivism philosophical paradigm: Implication for research, teaching and learning.

Agnew, M., Mertzman, T., Longwell-Grice, H., \& Saffold, F. (2008). Who's in, who's out: Examining race, gender and the cohort community. Journal of Diversity in Higher Education, 1(1), 20-32.

Ahmad, F., \& Greenhalgh-Spencer, H. (2017a). Trends in international mathematics and science study and gendered math teaching in Kuwait. Policy Futures in Education, 15(3), 357-340.

Ahmad, F., \& Greenhalgh-Spencer, H. (2017b). Trends in International Mathematics and Science Study and gendered math teaching in Kuwait. Policy Futures in Education, 15(3), 327-340.

Ahmad N, Asghar K. (2011). Attitude towards Biology and Its Effects on Student's Achievement. International Journal of Biology, 3(4).

Ahmed S. 2020. Education and Empowerment of Women in the GCC States.

Ajaja, O. P. (2013). Which strategy best suits biology teaching? Lecturing, concept mapping, cooperative learning or learning cycle? The Electronic Journal of Science Education, 17, 1-37.

Ajaja, O. P., \& Eravwoke, O. U. (2010). Effects of cooperative learning strategy on junior secondary school students achievement in integrated science. The Electronic Journal of Science Education, $14,1-18$.

Al-Fadhel H, Al-Jalahma A, Al-Muhanadi M. (2020) The reporting of technological readiness of higher education institutions in GCC Countries: A situational analysis of COVID-19 Crisis; IEEE. $p$ 296-301.

Al-Fadhli, S. (2008). Students' perceptions of E-Learning in Arab society: Kuwait University as a case study. E-Learning and Digital Media, 5(4), 418-428.

Al-Fadhli, S., \& Khalfan, A. (2009). Developing critical thinking in e-learning environment: Kuwait University as a case study. Assessment \& Evaluation in Higher Education, 34(5), 529-536.

Al-Fadhli SJE-L, media D. (2008). Students' perceptions of E-learning in Arab Society: Kuwait University as a case study. 5(4):418-428.

Al-Fadhli SJOjodla. (2009). Factors influencing the acceptance of distance learning: A case study of Arab Open University in Kuwait. 12(3).

Al-kaabi AF. (2016). Effects of collaborative learning on the achievement of students with different learning styles at Qatar University [Doctor of Philosophy]: Brunel University London.

Al-Kandari, A. (2006). To what extent science education objectives are presented in science teachers' lesson plan in Kuwait schools. The Educational Journal, 20, 80.

Al-Khaldi S. (2007). Education policies in GCC states. GRC Research Papers Series.

Al-Samarraie H, Saeed NJC, Education. (2018). A systematic review of cloud computing tools for collaborative learning: Opportunities and challenges to the blended-learning environment. 124:77-91.

Al-Sharhan, S. (2018). Kuwait. In A. S. Weber \& S. Hamlaoui (Eds.), E-Learning in the Middle East and North Africa (MENA) Region (pp. 193-224). Springer International Publishing. 
Alam, S., \& Jackson, L. (2013). A case study: Are traditional face-to-face lectures still relevant when teaching engineering courses? Int. J. Eng. Pedagog., 3, 9-15.

Almasri, F. (2022). Simulations to teach science subjects: Connections among students' engagement, self-confidence, satisfaction, and learning styles. Education and Information Technologies. https:// doi.org/10.1007/s10639-022-10940-w

Almasri F, Hewapathirana GI, Ghaddar F, Lee N, Ibrahim BJPo. (2021). Measuring attitudes towards biology major and non-major: Effect of students' gender, group composition, and learning environment. 16(5):e0251453.

Alonso, F., López, G., Manrique, D., \& Viñes, J. M. (2005). An instructional model for web-based e-learning education with a blended learning process approach. British Journal of Educational Technology, 36(2), 217-235.

Alsuwailan, Z. F. M. M. (2006). The impact of societal values on Kuwaiti women and the role of education. University of Tennessee.

Andrews-Graham DNA. (2018). The effect of online teaching on faculty after returning to the traditional classroom. Online Journal of Distance Learning Administration 21.

Armstrong MC. (2011). Perceptions on collaborative learning: A case study of female community college instructors.

Auerbach AJJ, Andrews TCJIjoSe. (2018). Pedagogical knowledge for active-learning instruction in large undergraduate biology courses: a large-scale qualitative investigation of instructor thinking. 5(1):1-25.

Austin AE. Vision and Change: Unpacking a Movement and Sharing Lessons Learned. . In: Smith D, editor; (2017); Boston, Massachusetts. American Association for the Advancement of Science

Avery Gomez, E., Wu, D., \& Passerini, K. (2010). Computer-supported team-based learning: The impact of motivation, enjoyment and team contributions on learning outcomes. Computers and Education, 55(1), 378-390.

Baram-Tsabari A, Kaadni AK. 2009. Gender Dependency and Cultural Independency of Science Interest in an Open and Distant Science Learning Environment. The International Review of Research in Open and Distributed Learning 10(2).

Barber M, Mourshed M, Whelan F. (2007). Improving education in the Gulf. . The McKinsey Quarterly. :39-47.

Barbieri, M. S., \& Light, P. H. (1992). Interaction, gender, and performance on a computer-based problem solving task. Learning and Instruction, 2(3), 199-213.

Barnett, J. E., \& Francis, A. L. (2012). Using higher order thinking questions to foster critical thinking: A classroom study. Educational Psychology Review, 32(2), 201-211.

Barone, C. (2011). Some things never change: Gender segregation in higher education across eight nations and three decades. Sociology of Education, 84(2), 157-176.

Beasley MA, Fischer MJJSPoE. (2012). Why they leave: The impact of stereotype threat on the attrition of women and minorities from science, math and engineering majors. 15(4):427-448.

Bensaid B, Brahimi T. (2020) Coping with COVID-19: higher education in the GCC countries; 2020. Springer. p 137-153.

BERA. (2014). BERA ethical guidelines. .

Biel, R., \& Brame, C. (2016). Traditional versus online biology courses: Connecting course design and student learning in an online setting. Journal of Microbiology \& Biology Education, 17(3), $417-422$.

Brownell, S. E., Kloser, M. J., Fukami, T., \& Shavelson, R. J. (2013). Context matters: Volunteer bias, small sample size, and the value of comparison groups in the assessment of research-based undergraduate introductory biology lab courses. Journal of Microbiology \& Biology Education, 14(2), $176-182$.

Burhanuddin, Bambang Budi W, Achmad S. (2020) Male and Female Student Perceptions on the Effectiveness of Online Courses at University. Advances in Social Science, Education and Humanities Research; 2020 2020-12-15T10:23:56.000Z. Atlantis Press. p 617-623.

Burkam, D. T., Lee, V. E., \& Smerdon, B. A. (1997). Gender and science learning early in high school: Subject matter and laboratory experiences. American Educational Research Journal, 34(2), 297-331.

Bystrov I, Panigrahi SKJJoCIiB, Government. (2021). Commitment of Higher Education Institutions to Sustainability Agenda: Evidences from GCC Countries. 27(2):4182-4189.

Cabrera, I., Villalón, J. J., \& Chávez, J. (2017). Blending communities and team-based learning in a programming course. IEEE Transactions on Education, 60, 288-295. 
Carli, L. L. (2001). Gender and social influence. Journal of Social Issues, 57(4), 725-741.

Carter LJSE. (2008). Sociocultural influences on science education: Innovation for contemporary times. 92(1):165-181.

Cavinato, A. G., Hunter, R. A., Ott, L. S., \& Robinson, J. K. (2021). Promoting student interaction, engagement, and success in an online environment. Analytical and Bioanalytical Chemistry, 413, 1513-1520.

Celik S, Bayrakceken S. (2012). The influence of an activity-based explicit approach on the Turkish prospective science teachers' conceptions of the nature of science. Australian Journal of Teacher Education, 37(4).

Cen, L., Ruta, D., Powell, L., Hirsch, B., \& Ng, J. (2016a). Quantitative approach to collaborative learning: Performance prediction, individual assessment, and group composition. International Journal of Computer-Supported Collaborative Learning, 11(2), 187-225.

Cen, L., Ruta, D., Powell, L., Hirsch, B., \& Ng, J. W. P. (2016b). Quantitative approach to collaborative learning: Performance prediction, individual assessment, and group composition. International Journal of Computer-Supported Collaborative Learning, 11, 187-225.

Cen L, Ruta D, Powell L, Ng J. (2014) Does gender matter for collaborative learning?; 2014 8-10 Dec. 2014. p 433-440

Clark-Ibáñez, M., \& Scott, L. (2008). Learning to Teach Online. Teaching Sociology., 36(1), 34-41.

Colbeck, C. L., Cabrera, A. F., \& Terenzini, P. T. (2001). Learning professional confidence: Linking teaching practices, students' self-perceptions, and gender. The Review of Higher Education., 24(2), 173-191.

Collins S, Simon S. (2006). A literature review of research conducted on young people's attitudes to science education and biomedical science. London, England: Wellcome Trust.

Conger, D., \& Long, M. C. (2010). Why are men falling behind? Gender gaps in college performance and persistence. The Annals of the American Academy of Political and Social Science., 627, 184-214.

Creasey, G., Ottlinger, K., Devico, K., Murray, T., Harvey, A., \& Hesson-McInnis, M. (1997). Children's affective responses, cognitive appraisals, and coping strategies in response to the negative affect of parents and peers. Journal of Experimental Child Psychology, 67(1), 39-56.

Crowe, A., Dirks, C., \& Wenderoth, M. P. (2008). Biology in bloom: Implementing bloom's taxonomy to enhance student learning in biology. CBE-Life Sciences Education, 7(4), 368-381.

Chang M-M, Lehman JDJCj. (2002). Learning foreign language through an interactive multimedia program: An experimental study on the effects of the relevance component of the ARCS model.81-98.

Chennabathni R, Rejskind G. (1998). Gender Issues in Collaborative Learning. Canadian Woman Studies 17.

Dakhli, M., Dinkha, J., \& Matta, M. (2010). Educational attainment and career success in the GCC: Does gender matter?. AUK occasional papers. American University of Kuwait., 4, 3-10.

Dakhli M, El-Zohairy D. (2013). Emerging Trends in Higher Education in the GCC: A Critical Assessment. Innovation in Business Education in Emerging Markets. London: Palgrave Macmillan UK. p 43-63.

Dawkins, Oehrtman, Mahavier. (2017). Professor goals and student experiences in an ibl real analysis course: a case study.

Ding N, Harskamp E. (2006). How partner gender influences female students' problem solving in physics education. . Journal of Science Education and Technology 15((5-6)):331-343.

Dogru, M., \& Kalender, S. (2007). Applying the subject cell through constructivist approach during science lessons and the teacher s view. International Journal of Environmental and Science Education, 2(1), 3-13.

Dori YJ. The Effect of Teaching the Cell Topic Using the Jigsaw Method on Students' Achievement and Learning Activity; 1995.

Duffy, T. M., \& Kirkley, J. R. (2003). Learner-centered theory and practice in distance education: Cases from higher education (p. 476). Routledge.

Eddy, S., Brownell, S., \& Wenderoth, M. (2014). Gender gaps in achievement and participation in multiple introductory biology classrooms. CBE Life Sciences Education, 13(3), 478-492.

Eddy SL, Brownell SE. (2016). Beneath the numbers: A review of gender disparities in undergraduate education across science, technology, engineering, and math disciplines. Physical Review Physics Education Research, 12(2). 
Eddy SL, Brownell SE, Thummaphan P, Lan MC, Wenderoth MP. (2015). Caution, Student Experience May Vary: Social Identities Impact a Student's Experience in Peer Discussions. CBE life sciences education, 14(4).

Eddy SL, Crowe AJ, Wenderoth MP, Freeman S. (2013). How should we teach tree-thinking? An experimental test of two hypotheses. Evolution: Education and Outreach, 6(1):13.

Field, T., Miguel, D., \& Sanders, C. (2002). Adolescents' parent and peer relationships. Adolescence, 37(145), 121-130.

Freeman, S., Eddy, S. L., McDonough, M., Smith, M. K., Okoroafor, N., Jordt, H., \& Wenderoth, M. P. (2014a). Active learning increases student performance in science, engineering, and mathematics. Proceedings of the National Academy of Sciences, 111(23), 8410.

Freeman S, Eddy SL, McDonough M, Smith MK, Okoroafor N, Jordt H, Wenderoth MP. (2014b). Active learning increases student performance in science, engineering, and mathematics. PNAS 111(23).

Gamoran A, Secada WG, Marrett CB. (2000). The organizational context of teaching and learning. Handbook of the Sociology of Education. Boston, MA: Springer US. p 37-63.

Gelbgiser D, Albert KJSP. 2018. Green for all? gender segregation and green fields of study in american higher education. 65(4):564-583.

Gnesdilow, D., Evenstone, A., Rutledge, J., Sullivan, S., \& Puntambekar, S. (2013a). Group work in the science classroom: How gender composition may affect individual performance. Human Behavior, 48, 587-596.

Gnesdilow D, Evenstone AL, Rutledge J, Sullivan S, Puntambekar S. Group Work in the Science Classroom: How Gender Composition May Affect Individual Performance; 2013b.

Gogoulou A, Gouli E, Grigoriadou M, Samarakou M, Chinou DJJoET, Society. (2007). A web-based educational setting supporting individualized learning, collaborative learning and assessment. 10(4):242-256.

Goldenfeld, N., \& Woese, C. (2007). Biology's next revolution. Nature, 445, 369.

González-Gómez, F., Guardiola, J., Rodríguez, Ó. M., \& Montero Alonso, M. Á. (2012). Gender differences in e-learning satisfaction. Computers \& Education, 58(1), 283-290.

Gormley DK, Colella C, Shell DLJNe. (2012). Motivating online learners using attention, relevance, confidence, satisfaction motivational theory and distributed scaffolding. 37(4):177-180.

Graham CR, Misanchuk M. (2004). Computer-mediated learning groups: Benefits and challenges to using groupwork in online learning environments. Online collaborative learning: Theory and practice: IGI Global. p 181-202.

Gratton-Lavoie, C., \& Stanley, D. (2009). Teaching and Learning Principles of Microeconomics Online: An Empirical Assessment. The Journal of Economic Education., 40(1), 3-25.

Grebennikov, L., \& Skaines, I. (2009). Gender and higher education experience: A case study. Higher Education Research \& Development., 28(1), 71-84.

Guo M, Nieswandt M, McEneaney E. (2018). Female students' academic engagement and achievement in science and engineering: Exploring the influence of gender grouping in small group work in design-based learning contexts in high school biology. 2017 ASEE Annual Conference \& Exposition.

Hagay, G., Baram Tsabari, A., Ametller, J., Cakmakci, G., Lopes, B., Moreira, A., \& Pedrosa de Jesus, H. (2013). The generalizability of students' interests in biology across gender, country and religion. Research in Science Education, 43, 895-919.

Halloun, I. A., \& Hestenes, D. (1985). Common sense concepts about motion. American Journal of Physics, 53(11), 1056-1065.

Hansen L. (1994). Talking about leaving: Factors contributing to high attrition rates among science, mathematics and engineering undergraduate majors: Final report to the Alfred P. Sloan Foundation on an Ethnographic Inquiry at Seven Institutions (Seymour, Elaine; Hewitt, Nancy M.). Journal of Chemical Education 71.

Harskamp, E., Ding, N., \& Suhre, C. (2008). Group composition and its effect on female and male problem-solving in science education. Educational Research, 50(4), 307-318.

Heble, A. (2007). Teaching literature online to Arab students using technology to overcome cultural restrictions. Arts and Humanities in Higher Education., 6, 219-226.

Hestenes, D., Wells, M., \& Swackhamer, G. (1992). Force concept inventory. The Physics Teacher, 30(3), 141-158. 
Hewapathirana, G. I., \& Almasri, F. (2022). Active learning compared with lecture-based pedagogies in gender and socio-cultural context-specific major and non-major biology classes. In Handbook of research on active learning and student engagement in higher education (pp. 293-319). IGI Global. https://doi.org/10.4018/978-1-7998-9564-0.ch014

Hoffmann, F., \& P O. (2009). A professor like me: The influence of instructor gender on college achievement. Journal of Human Resources, 44, 479-494.

Hogg, M. A., \& Abrams, D. (1988). Social Identifications: A Social Psychology of Intergroup Relations and Group Processes. Routledge.

Huffman S, Wilkinson K, Wiedmaier C, Crews T, Arn J, Hemby V. (2005). Synchronous Versus Asynchronous: Delivery of Online Instruction and the Factors that Lead to Success or Failure. EdMedia + Innovate Learning 2005. Montreal, Canada: Association for the Advancement of Computing in Education (AACE).

Iborra A, García Campos M, Margalef L, Samaniego V.( 2009). Generating collaborative contexts to promote learning and development. Collaborative Learning: Methodology, Types of Interactions and Techniques.

Indriwati SE, Susilo H, Hermawan IMS. (2019). Improving students' motivation and collaborative skills through Remap Jigsaw learning combined with modelling activities. Jurnal Pendidikan Biologi Indonesia 5(2).

Jinks JL, Morgan V. (1999). Children's perceived academic self-efficacy: An inventory scale. Clearing House, 72, 224-230. 72:224-230.

Johnson DW, Johnson RT, E. SM. (2000). Cooperative learning methods: A meta-analysis. 2000. . Cooperative Learning Center website.

Kalas, P., O’Neill, A., Pollock, C., \& Birol, G. (2013). Development of a meiosis concept inventory. CBE Life Science Education, 12(4), 655-664.

Karafyllis NC. (2015a). Tertiary education in the GCC countries (UAE, Qatar, Saudi Arabia): how economy, gender and culture affect the field of STEM. International Science and Technology Education 1st Edition ed: Routledge. p 22.

Karafyllis NC. (2015b). Why 'technology' is not universal: philosophical remarks on the language and culture issue of STEM education. In: Routledge, editor. International Science and Technology Education. 1st Edition ed. p 16.

Keengwe J, Kidd T. (2010). Towards best practices in online learning and teaching in higher education. Computer Science, 6(2).

Keller JM. 1984. The use of the ARCS model of motivation in teacher training. . In K.E. Shaw (Ed.) Aoet, editor. London: Kogan Page.

Keller JM. 2010. Motivational Design for Learning and Performance: Springer US.

Keller, M. M., Neumann, K., \& Fischer, H. E. (2017). The impact of physics teachers' pedagogical content knowledge and motivation on students' achievement and interest. Journal of Research in Science Teaching, 54(5), 586-614.

Kelly R. (2012). Synchronous and Asynchronous Learning Tools: 15 Strategies for Engaging Online Students Using Real-time Chat, Threaded Discussions and Blogs. . Faculty Focus

Khan F, Aradi W, Schwalje W, Buckner E, Fernandez-Carag MJIJotr. (2017). Women's participation in technical and vocational education and training in the Gulf States. 15(3):229-244.

Kim, D. S., Lee, H., \& Skellenger, A. (2012). Comparison of levels of satisfaction with distance education and on-campus programs. Journal of Visual Impairment \& Blindness, 106(5), 275-286.

Kim, H. S. (2008). Culture and the cognitive and neuroendocrine responses to speech. Journal of Personality and Social Psychology, 94(1), 32-47.

Kim, J., \& Park, C.-Y. (2020). Education, skill training, and lifelong learning in the era of technological revolution: A review. Asian-Pacific Economic Literature, 34(2), 3-19.

Kim, J. S. (2005). The effects of a constructivist teaching approach on student academic achievement, selfconcept, and learning strategies. Asia Pacific Education Review, 6(1), 7-19.

Kuit, T., \& Fildes, K. (2014). Changing curriculum design to engage students to develop lifelong learning skills in biology. International Journal of Innovation in Science and Mathematics Education, 22, 19.

Lansari, A., Tubaishat, A., \& Al-Rawi, A. (2007). Using an outcome-based information technology curriculum and an e-learning platform to facilitate student learning. Issues in Informing Science and Information Technology, 4, 461-471.

Lantolf JP, Thorne SL. 2006. Sociocultural theory and genesis of second language development: Oxford: Oxford University Press, 2006. 
Le, H., Janssen, J., \& Wubbels, T. (2017). Collaborative learning practices: Teacher and student perceived obstacles to effective student collaboration. Cambridge Journal of Education, 48(1), 103-122.

Li L. (2020). Education supply chain in the era of Industry 4.0. Systems Research and Behavioral Science 37(4):579-592.

Light, P., Littleton, K., Bale, S., Joiner, R., \& Messer, D. (2000). Gender and social comparison effects in computer-based problem solving. Learning and Instruction, 10(6), 483-496.

Lightfoot MD. (2014). Education Reform for the Knowledge Economy in the Middle East. A study of education policy making and enactment in The Kingdom of Bahrain. . London. .

Lipsey M, Puzio K, Yun C, Hebert M, Steinka-Fry K, Cole M, Roberts M, Anthony K, MD B. (2012). Translating the statistical representation of the effects of education interventions into more readily interpretable forms. National Center for Special Education Research, Institute of Education Sciences.

Lord, T. R. (1997). A comparison between traditional and constructivist teaching in college biology. Innovative Higher Education., 21, 197-216.

Lundeberg, M. A., \& Moch, S. D. (1995). Influence of Social Interaction on Cognition: Connected Learning in Science. The Journal of Higher Education., 66(3), 312-335.

Mahboob A, Elyas T. (2017). Challenges to Education in the GCC during the 21st Century: Gulf Research Centre Cambridge

Mansour N. (2013). Modelling the sociocultural contexts of science education: The teachers' perspective. Research in Science Education, 43:347-369.

Mansour N, Al-Shamrani S. (2015a). Science education in the arab gulf states visions, sociocultural contexts and challenges.

Mansour N, Al-Shamrani S. (2015b). Science Education in the Arab Gulf States. Visions, Sociocultural Contexts and Challenges.

Marjoribanks, K. (1996). Family Socialisation and Children's School Outcomes: An investigation of a parenting model. Educational Studies, 22(1), 3-11.

Márquez LMT, Llinás JG, Macías FS. (2017a). Collaborative Learning: Use Of The Jigsaw Technique In Mapping Concepts Of Physics. Problems of Education in the 21st Century 75(1):92-101.

Márquez LMT, Llinás JG, Macías FS. 2017b. Collaborative learning: use of the jigsaw technique in mapping concepts of physics. Problems of education in the 21stcentury 75(1):201.

Martin, A. J., Marsh, H. W., McInerney, D. M., Green, J., \& Dowson, M. (2007). Getting Along with Teachers and Parents: The Yields of Good Relationships for Students' Achievement Motivation and SelfEsteem. Australian Journal of Guidance and Counselling, 17(2), 109-125.

Martin, F., Parker, M. A., \& Deale, D. F. (2012). Examining Interactivity in Synchronous Virtual Classrooms. International Review of Research in Open and Distributed Learning, 13(3), 227-261.

McClusky B. (2017). Investigating the relationships between education and culture for female students in tertiary settings in the UAE: Edith Cowan University

Means TB, Jonassen DH, Dwyer FMJEtr, development. (1997). Enhancing relevance: Embedded ARCS strategies vs. purpose. 45(1):5-17.

Microsoft Teams. (2016). Introducing Microsoft teams. .

Milliken, F., \& J., Martins L, L. (1996). Searching for Common Threads: Understanding the Multiple Effects of Diversity in Organizational Groups. Academy of Management Review, 21(2), 402-433.

Mitchell SM, Anderson WL, Sensibaugh CA, Osgood M. (2011). What Really Matters: Assessing Individual Problem-Solving Performance in the Context of Biological Sciences. International Journal for the Scholarship of Teaching and Learning 5(1).

Mohamad Said, M. N. H. B., Tahir, A. M. F., \& Zaid, N. M. (2014). The Process of Incorporating Online Collaborative Learning: An Analysis of Malaysian Tertiary ICT Educators' Perceptions. Advanced Science Letters, 20(5), 2142-2146.

Momsen, J. L., Long, T. M., Wyse, S. A., \& Ebert-May, D. (2010). Just the facts? Introductory undergraduate biology courses focus on low-level cognitive skills. CBE Life Sciences Education., 9(4), 435-440.

Myaskovsky, L., Unikel, E., \& Dew, M. A. (2005). Effects of gender diversity on performance and interpersonal behavior in small work groups. Sex Roles, 52(9-10), 645-657.

Naime-Diefenbach BN. (1991). Validation of attention and confidence as independent components of the ARCS motivational model: The Florida State University.

Nasr AR, Soltani KA. (2011). Attitude towards biology and its effects on student's achievement. International Journal of Biology. 3(4).

Norman ZD. (2020). Understanding the Effect of Distance Learning vs. Face-to-Face Learning Experiences on Students' Engagement in Higher Education: Gonzaga University. 
Omari BKA. (2017). Online Education And Economic Growth In Gcc. International Journal of Social Economic Research, 7(4):26-46.

Opdecam, E., Everaert, P., \& Van Keer, H. (2014). Preferences for team learning and lecture-based learning among first-year undergraduate accounting students. 9315-6. Research in Higher Education, 55, 400-432.

Örnek F. (2015). Cultures effects on students attitudes towards science. Education policy, management and quality $7(1)$.

Osborne J, Dillon J. (2008). Science education in Europe: Critical reflections: London: The Nuffield Foundation.

Owens DC, Sadler TD, Barlow AT, Smith-Walters CJRiSE. (2020). Student motivation from and resistance to active learning rooted in essential science practices. 50(1):253-277.

Palsole, S., \& Awalt, C. (2008). Team-based learning in asynchronous online settings. New Directions for Teaching and Learning, 116, 87-95.

Parrish, C. W., Williams, D. S., \& Estis, J. M. (2021). Integrated online team-based learning: Using synchronous engagement and asynchronous flexibility to implement TBL online. New Directions for Teaching and Learning, 2021(165), 91-105.

Paul J, Jefferson F. (2019). A comparative analysis of student performance in an online vs. face-to-face environmental science course from 2009 to 2016. Frontiers in Computer Science 1(7).

Petrescu A-MA, Gorghiu G, Draghicescu LM. (2018). The advantages of collaborative learning in science lessons. 15th Edition of the International Conference on Sciences of Education, Studies and Current Trends in Science of Education, ICSED 2017, 9-10 June 2017, Suceava (Romania). p 326-333.

Pham Thi Hong T. (2011). Issues to consider when implementing student-centred learning practices at Asian higher education institutions. Journal of Higher Education Policy and Management, 33(5):519-528.

Pirmohamed, S., Debowska, A., \& Boduszek, D. (2017). Gender differences in the correlates of academic achievement among university students. Journal of Applied Research in Higher Education., 9(2), $313-324$

Powell, K. (2003). Science education: Spare me the lecture. Nature, 425(6955), 234-236.

Ramirez, I. A. L. (2018). The Effects of Reality Pedagogy on the Academic Performance and Motivation to Learn of Grade 7 Physics Students. International Journal on Language, Research and Education Studies, 2(2), 176-194.

Ratner, B. (2009). The correlation coefficient: Its values range between $+1 / \hat{a}^{\wedge}$ ' 1 , or do they? Journal of Targeting, Measurement and Analysis for Marketing, 17(2), 139-142.

Reeves, T., \& Reeves, P. (1997). Effective Dimensions on Interactive Learning on the World Wide Web. In B. H. Khan (Ed.), Web-Based Instruction: Englewood Cliffs (pp. 59-66). Educational Technology Publications.

Reseach \& Markets. (2017). Middle East online education \& e-learning market size, demand, opportunity \& growth outlook 2023. . Dublin.: Research and Markets.

Roberts TS. 2003. Online Collaborative Learning: Theory and Practice.

Robinson, N. S. (1995). Evaluating the Nature of Perceived Support and its Relation to Perceived Self-Worth in Adolescents. Journal of Research on Adolescence, 5(2), 253-280.

Rudestam, K. E. (2004). Distributed Education and the Role of Online Learning in Training Professional Psychologists. Professional Psychology: Research and Practice, 35(4), 427-432.

Rudestam KE, Schoenholtz-Read J. 2010. Handbook of Online Learning: SAGE Publications.

Ruegg W. (1992). A History of The University in Europe CAMBRIDGE UNIVERSITY PRESS.

Rummel N, Spada HJTjotLS. (2005). Learning to collaborate: An instructional approach to promoting collaborative problem solving in computer-mediated settings. 14(2):201-241.

Ruta D. (2014). Does gender matter for collaborative learning? International Conference of Teaching, Assessment and Learning (TALE). Wellington, New Zealand.

Saba, F. (2005). Critical Issues in Distance Education: A report from the United States. Distance Education., 26(2), 255-272.

Samuel J, Hinson J. (2010). Online asynchronous team-based learning: A phased design to enhance student performance. In: (Eds.). IDGBD, editor. Proceedings of SITE 2010 - Society for Information Technology \& Teacher Education International Conference. San Diego, CA, USA: Association for the Advancement of Computing in Education (AACE). p 2366-2370.

Scager K, Boonstra J, Peeters T, Vulperhorst J, Wiegant F. (2016). Collaborative learning in higher education: Evoking positive interdependence. CBE life sciences education 15(4):ar69.

Scharf, M. T. (2015). Comparing Student Cumulative Course Grades, Attrition, and Satisfaction in Traditional and Virtual Classroom Environments. Arizona Northcentral University. 
Siann, G., \& Macleod, H. (1986). Computers and children of primary school age: Issues and questions. British Journal of Educational Technology, 17(2), 133-144.

Siemens, G., Gašević, D., \& Dawson, S. (2015). Preparing for the digital university: a review of the history and current state of distance, blended and online learning. Athabasca University Press.

Silva ECe, Lino-Neto T, Ribeiro E. 2021. Going virtual and going wide: comparing Team-Based Learning inclass versus online and across disciplines. . Education and Information Technologies.

Singera, F. M., Samihaianb, F., Holbrookc, J., \& Crisand, A. (2014). Developing a competence-based curriculum for the 21st century: The case of Kuwait. Procedia - Social and Behavioral Sciences, 128, 475-481.

Slavin. (1996a). Research on cooperative learning and achievement: what we know, what we need to know. Contemporary Educational Psychology, 21:43-69.

Slavin RE. (1996b). Research on cooperative learning and achievement: What we know, what we need to know. Contemporary Educational Psychology, 21(1):43-69.

Slavin RE. 2010. Instruction based on cooperative learning.344-360.

Song, H.-g, Restivo, M., van de Rijt, A., Scarlatos, L., Tonjes, D., \& Orlov, A. (2015). The hidden gender effect in online collaboration: An experimental study of team performance under anonymity. Computers in Human Behavior, 50, 274-282.

Sormunen-Jones, C., Chalupa, M. R., \& Charles, T. A. (2000). The dynamics of gender impact on group achievement. Delta Pi Epsilon Journal, 42(3), 154.

Springer, L., Stanne, M. E., \& Donovan, S. (1998). Measuring the success of small-group learning in college level SMET teaching: A meta-analysis. Review of Educational Research., 69, 21-51.

Struyf, A., De Loof, H., Boeve-de Pauw, J., \& Van Petegem, P. (2019). Students' engagement in different STEM learning environments: Integrated STEM education as promising practice? International Journal of Science Education, 41(10), 1387-1407.

Stump, Hilpert, Husman, Chung, Kim. (2011a). Collaborative learning in engineering students: gender and achievement. Journal of Engineering Eduation, 11(3):1-24.

Stump, G. S., Hilpert, J. C., Husman, J., Chung, W.-t, \& Kim, W. (2011). Collaborative learning in engineering students: Gender and achievement. Journal of Engineering Education, 100(3), 475-497.

Sun, A., \& Chen, X. (2016). Online education and its effective practice: A research review. Journal of Information Technology Education, 15, 157-190.

Sunitha.G, .H.M K. (2018). Impact of collaborative learning among undergraduate medical students. IOSR Journal of Research \& Method in Education, 8(12).

Swanson, J. A., Renes, S. L., \& Strange, A. T. (2021). Collaborative learning: Collegiate pedagogy utilizing web conferencing (pp. 253-267). Springer.

Szymkowiak A, Melović B, Dabić M, Jeganathan K, Singh Kundi G. (2021). Information technology and Gen $\mathrm{Z}$ : The role of teachers, the internet, and technology in the education of young people. Technology in Society, 65:101565.

Takeda, K., Takahashi, K., Masukawa, H., \& Shimamori, Y. (2017). Influence on learning of a collaborative learning method comprising the Jigsaw method and problem-based learning (PBL). Yakugaku Zasshi: Journal of the Pharmaceutical Society of Japan., 137(6), 659-664.

Takeda, S., \& Homberg, F. (2014). The effects of gender on group work process and achievement: An analysis through self- and peer-assessment. British Educational Research Journal, 40(2), 373-396.

Tanner, K., \& Allen, D. (2004). Approaches to biology teaching and learning: Learning styles and the problem of instructional selection-engaging all students in science courses. Cell Biology Education, 3(4), 197-201.

Tanner, K., \& Allen, D. (2006). Approaches to biology teaching and learning: On integrating pedagogical training into the graduate experiences of future science faculty. CBE Life Sciences Education, 5(1), 1-6.

Tanner, K. D. (2013). Structure matters: Twenty-one teaching strategies to promote student engagement and cultivate classroom equity. CBE Life Sciences Education, 12(3), 322-331.

Tekbiyık A. (2015). The use of Jigsaw collaborative learning method in teaching socio-scientific issues: The Case of Nuclear Energy. Journal of Baltic Science Education 14.

The World Bank. (2019). Expectations and aspirations. A new framework for education in the Middle East and North Africa. In: Ledent S, editor. Washington, DC.: International Bank for Reconstruction and Development.

Thirteen Edition Online. (2004). Constructivism as a paradigm for teaching and learning.: Educational Broadcasting Corporation.

Thomas P, Setiaji KJDP. (2014). E-learning dengan pendekatan kooperatif tipe jigsaw untuk meningkatkan aktivitas dan hasil belajar mahasiswa. 9(1). 
Thorne K. (2003). Blended learning: how to integrate online \& traditional learning: Kogan Page Publishers.

Tubaishat A, Bhatti A, El-Qawasmeh EJIiis, technology i. (2006). ICT experiences in two different Middle Eastern universities. 3.

van der Linden, J., Erkens, G., Schmidt, H., \& Renshaw, P. (2000). Collaborative learning (pp. 37-54). Springer.

Vision and Change in Undergraduate Biology Education. (2010). Association for the Advancement of Science.

Vygotsky, L. (1978). Mind in society. Harvard University Press.

Vygotsky LS. (1997). The collected works of LS Vygotsky: Problems of the theory and history of psychology: Springer Science \& Business Media.

Wang F, Burton JKJJoETD, Exchange. 2010. Collaborative learning problems and identity salience: A mixed methods study. 3(1):1.

Wang, M. T., \& Degol, J. L. (2017). Gender gap in science, technology, engineering, and mathematics (STEM): Current knowledge, implications for practice, policy, and future directions. Educational Psychology Review, 29(1), 119-140.

WAnG QJC, Education. (2009). Design and evaluation of a collaborative learning environment. 53(4):1138-1146.

Wang Y, Chen N-S. (2007). Online Synchronous language learning: SLMS over the Internet. Innovate: Journal of Online Education, 3(3).

Weber AS. (2010). Web-based learning in Qatar and the GCC States.: Center for international and regional studies. Georgetown University School of Foreign Service in Qatar.

Wehrwein E, A. , Lujan H, L. , DiCarlo S, E. . (2007). Gender differences in learning style preferences among undergraduate physiology students. Advances in Physiology Education, 31(2):153-157.

Wickman, P.-O., \& Östman, L. (2002). Learning as discourse change: A sociocultural mechanism. Science Education, 86(5), 601-623.

Woese, C. R. (2004). A new biology for a new century. Microbiology and Molecular Biology Reviews, 68(2), 6173-6186.

Wood, W. B. (2009). Innovations in teaching undergraduate biology and why we need them. Annual Review of Cell and Developmental Biology, 25, 93-112.

World Economic Forum. (2020). How has technology changed - and changed us - in the past 20 years? In: Hillyer MUSMS, World Economic Forum., editor. Pioneers of Change Summit. DIGITAL MEETING.

Xie BJJotASfIS, Technology. (2011). Older adults, e-health literacy, and collaborative learning: An experimental study. 62(5):933-946.

Xie, Y., Fang, M., \& Shauman, K. (2015a). STEM Education. Annu Rev Sociol, 41, 331-357.

Xie Y, Fang M, Shauman K. (2015b). STEM Education. Annual Review of Sociology 41(1):331-357.

Zhan, Z., Fong, P. S. W., Mei, H., \& Liang, T. (2015a). Effects of gender grouping on students' group performance, individual achievements and attitudes in computer-supported collaborative learning. Computers in Human Behavior, 48, 587-596.

Zhan, Z., Fong, P. S. W., Mei, H., \& Liang, T. (2015b). Effects of gender grouping on studentsâ€TM group performance, individual achievements and attitudes in computer-supported collaborative learning. Computers in Human Behavior, 48, 587-596.

Zhan, Z., Xu, F., \& Ye, H. (2011). Effects of an online learning community on active and reflective learners' learning performance and attitudes in a face-to-face undergraduate course. Computers \& Education, 56(4), 961-968.

Publisher's note Springer Nature remains neutral with regard to jurisdictional claims in published maps and institutional affiliations.

\section{Authors and Affiliations}

\section{Firas Almasri ${ }^{1,2}$ (D)}

1 Centre for Education Studies, University of Warwick, Coventry, Coventry CV4 7AL, UK

2 Department of Mathematics and Natural Sciences, Gulf University for Science and Technology, Hawally, Kuwait 